\title{
Materials nanoarchitectonics at two-dimensional liquid interfaces
}

\author{
Katsuhiko Ariga ${ }^{* 1,2}$, Michio Matsumoto ${ }^{1}$, Taizo Mori, ${ }^{1,2}$ and Lok Kumar Shrestha ${ }^{1}$
}

Review

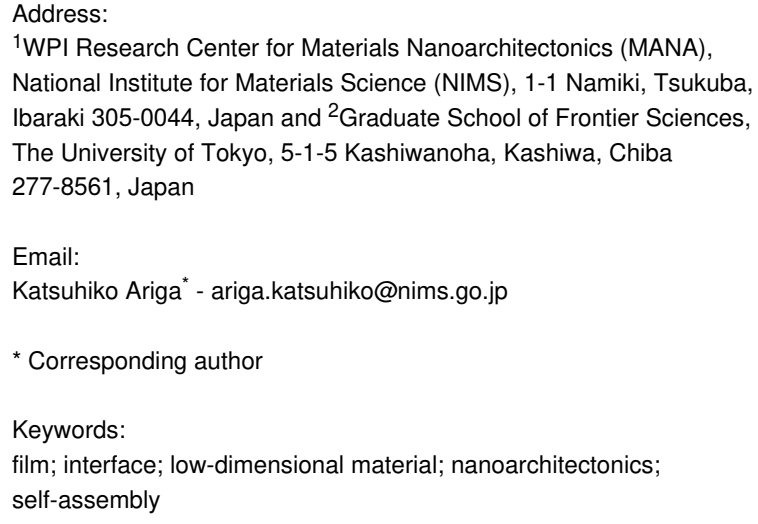

Beilstein J. Nanotechnol. 2019, 10, 1559-1587. doi:10.3762/bjnano. 10.153

Received: 23 February 2019

Accepted: 16 July 2019

Published: 30 July 2019

This article is part of the thematic issue "Low-dimensional materials and systems".

Guest Editor: S. Walia

(C) 2019 Ariga et al.; licensee Beilstein-Institut. License and terms: see end of document.

\begin{abstract}
Much attention has been paid to the synthesis of low-dimensional materials from small units such as functional molecules. Bottomup approaches to create new low-dimensional materials with various functional units can be realized with the emerging concept of nanoarchitectonics. In this review article, we overview recent research progresses on materials nanoarchitectonics at two-dimensional liquid interfaces, which are dimensionally restricted media with some freedoms of molecular motion. Specific characteristics of molecular interactions and functions at liquid interfaces are briefly explained in the first parts. The following sections overview several topics on materials nanoarchitectonics at liquid interfaces, such as the preparation of two-dimensional metal-organic frameworks and covalent organic frameworks, and the fabrication of low-dimensional and specifically structured nanocarbons and their assemblies at liquid-liquid interfaces. Finally, interfacial nanoarchitectonics of biomaterials including the regulation of orientation and differentiation of living cells are explained. In the recent examples described in this review, various materials such as molecular machines, molecular receptors, block-copolymer, DNA origami, nanocarbon, phages, and stem cells were assembled at liquid interfaces by using various useful techniques. This review overviews techniques such as conventional Langmuir-Blodgett method, vortex Langmuir-Blodgett method, liquid-liquid interfacial precipitation, instructed assembly, and layer-by-layer assembly to give low-dimensional materials including nanowires, nanowhiskers, nanosheets, cubic objects, molecular patterns, supramolecular polymers, metal-organic frameworks and covalent organic frameworks. The nanoarchitecture materials can be used for various applications such as molecular recognition, sensors, photodetectors, supercapacitors, supramolecular differentiation, enzyme reactors, cell differentiation control, and hemodialysis.
\end{abstract}




\section{Review}

\section{Introduction: nanoarchitectonics for low-dimensional materials}

To realize a sustainable society, there are many challenges to overcome in the next 30 years: fulfilling the needs regarding energy consumption, reducing unnecessary emissions, protecting the environment, and maximizing the efficiency of processes [1]. Various molecular technologies including chemical syntheses [2-6], ultrafine fabrications [7-11], physical analyses [12-16], materials productions [17-24], energy and environmental improvements [25-31], and biotechnological and biomedical developments [32-37] have been explored to achieve these objectives. One of the common key concepts for all these developments is regulating functional molecular systems with high spatial precision, which can often induce the efficient production, transmission, and conversion of materials, energies, and information [38]. In those examples, anisotropies in spatially defined materials or systems trigger directional and efficient flows of signals and energies. Despite many reported examples to create highly sophisticated molecular systems, there is still only a limited number of examples in which functional molecular systems are oriented or spatially confined in the bulk [39]. From these viewpoints, functional materials with low-dimensionality become a relevant part of these technologies.

Low-dimensional materials have been extensively explored because they often exhibit unique and superior properties due to quantum effects and anisotropic effects [40-44] (Figure 1). Synthetic methodologies to yield nanoparticles and zero-dimensional materials have been developed using conventional chemical methods and/or physical perturbations such as microwave and plasma irradiation [45-51]. Carbon nanotubes, representative one-dimensional objects, were produced using catalysts as well [52-55]. Recently, two-dimensional materials such as graphene and $\mathrm{MoS}_{2}$ nanosheets attracted the interests of researchers because of their superior electric/electrochemical properties that make them suitable for energy and electrochemical applications [56-60]. The works include the use of twodimensional metal oxide nanosheets for artificial photosynthesis systems, i.e., photocatalytic water splitting and fixation of carbon dioxide, which were recently reviewed by Maeda and Mallouk [61].

Despite these many intriguing demonstrations of two-dimensional materials, most of the examples reported so far utilize two-dimensional sheet materials synthesized in a top-down manner, and there is only a limited number of examples using bottom-up approaches [62]. In bottom-up approaches lowdimensional materials are constructed from small precursors such as functional molecules in order to obtain novel lowdimensional materials with various functional units [63-68]. The essential processes within these bottom-up approaches are self-assembly and self-organization based on supramolecular chemistry [69]. These supramolecular mechanisms can be widely observed in various species including small molecules, nanomaterials, and biomolecules [70-75]. Despite this generality, there are still many nontrivial fundamental challenges, which are actively studied using the quantitative analysis of self-assembly processes proposed by Hiraoka [76] and the temporal control of supramolecular polymerization by Dhiman

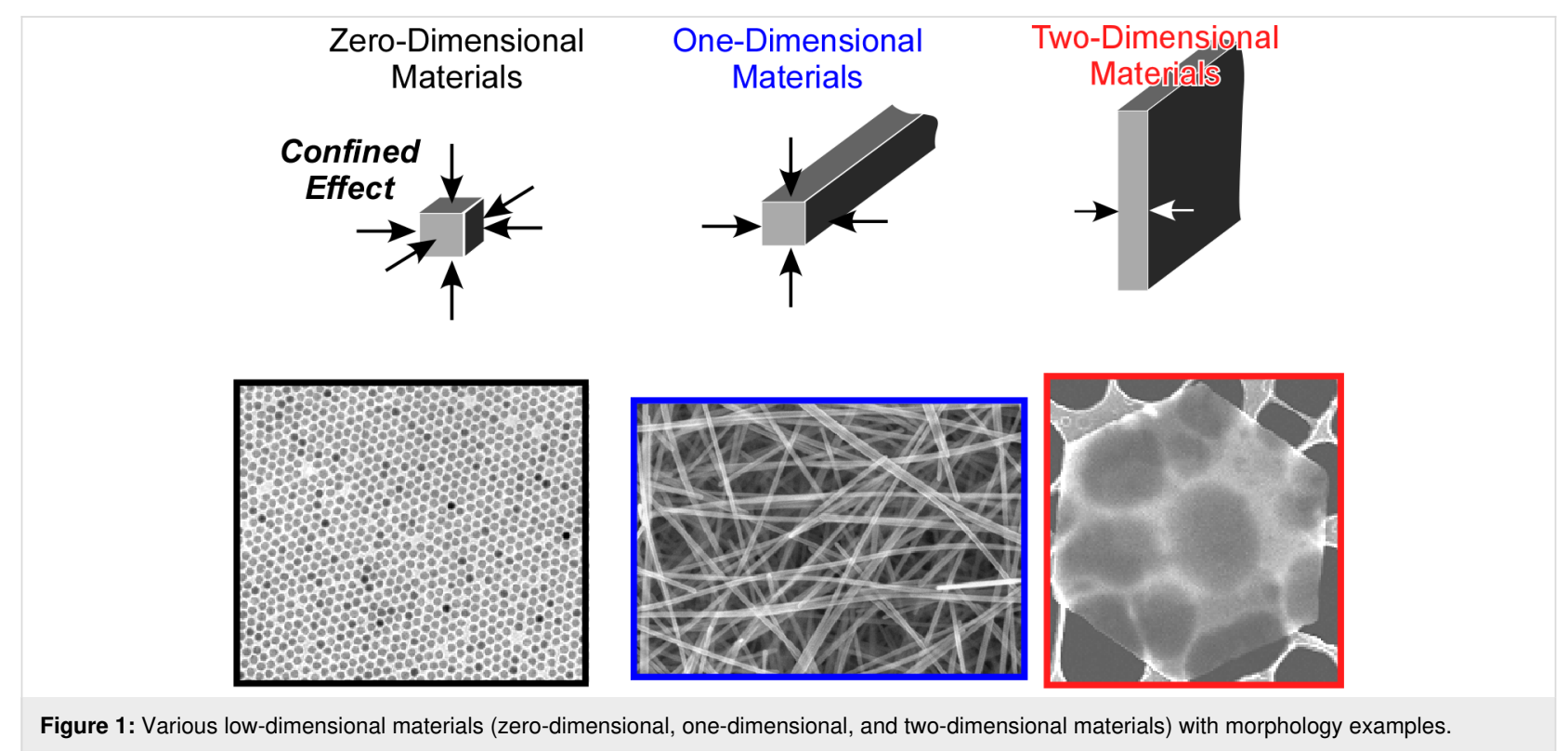


and George [77]. Shimizu summarized various parameters regulating the self-assembly of lipid molecules for producing structurally well-regulated one-dimensional nanotubes [78]. Selfassembled and polymerized materials are often used in sensing devices utilizing molecular imprinting mechanisms [79]. Twodimensional films made of assemblies of ion-recognizing macrocyclic host molecules, ion-exchangers, and indicative dyes were incorporated in an optode system detecting caesium ions in tap water and seawater [80]. Photo-controllable molecular devices were successfully fabricated using two-dimensional self-assembled monolayer technology as recently reviewed by Suda [81].

Hierarchic functional systems fabricated with low-dimensional materials are actively investigated. For example, Lvov and co-workers reported the immobilization of small functional materials such as metal clusters and metal catalysts within onedimensional halloysite clay nanotubes to make them work under appropriate protection from external disturbances [8284]. Zhong and Xu summarized, in their recent review, the preparation of metal nanoparticles for hydrogen generation from liquid chemical hydrides [85]. In their review, the usage of effective catalysts within low-dimensional cages of metalorganic frameworks was reported. Jayavel, Shrestha, and co-workers demonstrated the enhanced performance of electrochemical supercapacitors using composites of cobalt oxide nanoparticles and reduced graphene oxide, which are zerodimensional and two-dimensional nanomaterials, respectively [86]. Leong and co-workers reported a sophisticated strategy to realize chemotherapy targeting at cancer cells using the controlled assembly and disassembly of layer-by-layer hybrid structures made of two dimensional $\mathrm{MoS}_{2}$ nanosheets with DNA [87].

The preparation of functional low-dimensional materials requires preservation of nanoscale features in their construction processes. This characteristic is also important in the emerging concept of nanoarchitectonics, which was initiated by Masakazu Aono in 2000 [88-91]. This concept is even regarded as the next step of nanotechnology combining various research disciplines such as organic synthesis, physical materials control, supramolecular chemistry, and biology [92-94]. In this concept, materials and systems can be engineered through the manipulation of atoms and molecules, self-assembly and self-organization, and field-controlled organization (Figure 2). Unlike the well-established microfabrication and other techniques at microscopic and macroscopic levels, the nanoarchitectonics procedures have to take into account several uncertainties such as thermal fluctuations, quantum effects, and uncontrolled mutual interactions at the nanoscale $[95,96]$.

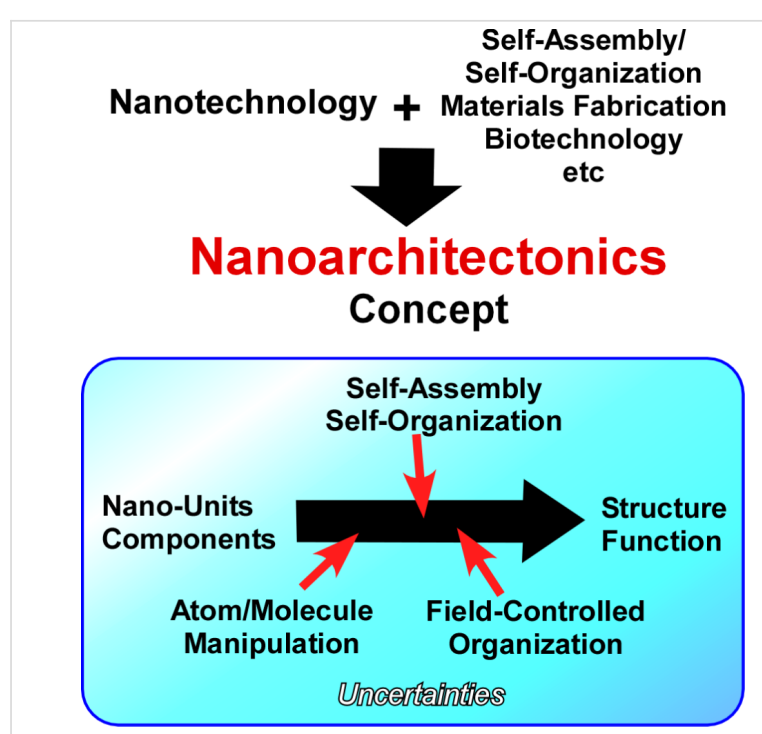

Figure 2: Outline of nanoarchitectonics strategies to obtain structures and functions through the manipulation of atoms and molecules, selfassembly and self-organization, and field-controlled organization.

Because of its general applicability, research approaches with the nanoarchitectonics concept are now seen in many recent publications in various fields including materials production [97,98], structural fabrication [99-108], sensing [109-112], energy applications [113-117], environmental protection [118,119], catalysts [120,121], biology [122-124], and biomedical applications $[125,126]$. For example, the following recent research works on low-dimensional materials have been carried out using the nanoarchitectonics concept: Hasegawa and co-workers used atom-manipulation nanoarchitectonics (controlled single atom/ion transfer) to regulate the number of dopant atoms in one-dimensional solid electrolyte nanodots $\left(\alpha-\mathrm{Ag}_{2+\delta} \mathrm{S}\right)$ [127]. The nanoarchitectonic construction of onedimensional nanowires from II-VI semiconductors was demonstrated for the use as wavelength division multiplexer as reported by Yan, Zhao and co-workers [128]. Other one-dimensional functional structures such as porphyrin-functionalized DNA (by Stulz [129]), DNA-based complex structures for ultrasensitive mercury detection (by Govindaraju and co-workers [130]), self-assembled chiral twisted and helical nanofibers (by Liu and co-workers [131]), and supramolecular assemblies with short peptides and their bio-functions (by Yan and co-workers [132]) have been investigated. As examples of research efforts regarding two-dimensional nanoarchitectures, the enhanced reduction of nitrogen oxides by facet-engineered two-dimensional $\mathrm{CuO}$ petal assemblies (by Abe and co-workers [133]), perovskite nanosheets and their layer-by-layer assemblies as high- $k$ dielectric/ferroelectric materials (by Osada and Sasaki [134]), the manipulation of transition-metal dichalcogenides nanosheets for the usage in energy storage/conversion applications (by Xu, Lee, and co-workers [135]) and substrate chan- 
nelling between enzymes with graphene oxide nanosheets (by Yang and co-workers [136]) can be mentioned.

The nanoarchitectonics bottom-up approaches preserving the nanostructural properties are highly useful for the fabrication of low-dimensional materials and the subsequent construction of functional structures from low-dimensional materials. Especially, nanoarchitectonics fabrication in motional restricted and dimensionally confined media would be beneficial for the production of low-dimensional materials. Therefore, in this review article, we overview recent research progresses on materials nanoarchitectonics at two-dimensional liquid interfaces, which are dimensionally restricted media with certain degrees of motional freedom $[137,138]$. In the next section, specific features of molecular interactions and functions at liquid interfaces, as well as two-dimensional molecular patterning, are briefly explained. In the following sections, several topics of materials nanoarchitectonics at liquid interfaces such as the preparation of two-dimensional metal-organic frameworks (MOFs) and covalent organic frameworks (COFs), the fabrication of multi-dimensionally structured nanocarbons and their assemblies, and the interfacial nanoarchitectonics of biomaterials are exemplified.

\section{Unique features of liquid interfaces and formation of two-dimensional patterns \\ 2.1 Unique features of liquid interfaces}

Gas-liquid interfaces and liquid-liquid interfaces are categorized as interfacial environments with certain degrees of freedom of molecular mobility (dynamism). These interfaces with liquids have several intrinsic features: (i) They are environments of two different phases; (ii) they exhibit a discontinuous change of the dielectric constant; (iii) they are highly directional environments restricting molecular motion only in the vertical direction. These features create several unique features that are described in the following.

Interfaces are generally formed by two immiscible phases. In many research examples utilizing liquid-liquid interfaces, the immiscible liquids dissolve different species that can only come into contact at the interface. At gas-liquid interfaces, insoluble components remain only at the interface and interact with other molecules (or materials) diffused from the underneath liquid phase. These circumstances can induce the generation of lowdimensional materials. In addition, physics and chemistry of molecular interactions at liquid interfaces are significantly different from those observed in homogeneous solutions [139141].

Unique features of molecular interactions can be clearly observed at the air-water interface [142-144]. Although molecu- lar recognition via hydrogen bonding are quite difficult in a highly polar aqueous media, the molecular recognition of sugars [145,146], peptides [147-149], amino acids [150], nucleic acid bases $[151,152]$, and nucleotides $[153,154]$ is accomplishable at the air-water interface even though this recognition relies on hydrogen bonding. Systematic studies on binding constants of a fixed recognition pair, phosphate and guanidinium ions, revealed a significant influence of the interfacial environment on the interactions between the molecules embedded at various interfaces (Figure 3) [155]. The binding constant between phosphate and guanidinium ions dispersed in water was reported as $1.4 \mathrm{M}^{-1}$ [156]. Altering the recognition media to rather disorganized mesoscopic interfaces drastically increases the binding constants. The binding constants of phosphate derivatives to the surfaces of guanidinium-functionalized aqueous micelles and lipid bilayers reaches values of $10^{2}$ to $10^{4} \mathrm{M}^{-1}$. Surprisingly, the binding constant of the same recognition pair further increases to $10^{6}$ to $10^{7} \mathrm{M}^{-1}$ when a macroscopic less dynamic interface, the air-water interface, is used as the recognition medium $[157,158]$. Similarly, strongly enhanced binding constants were commonly observed at the air-water interface for various recognition pairs.

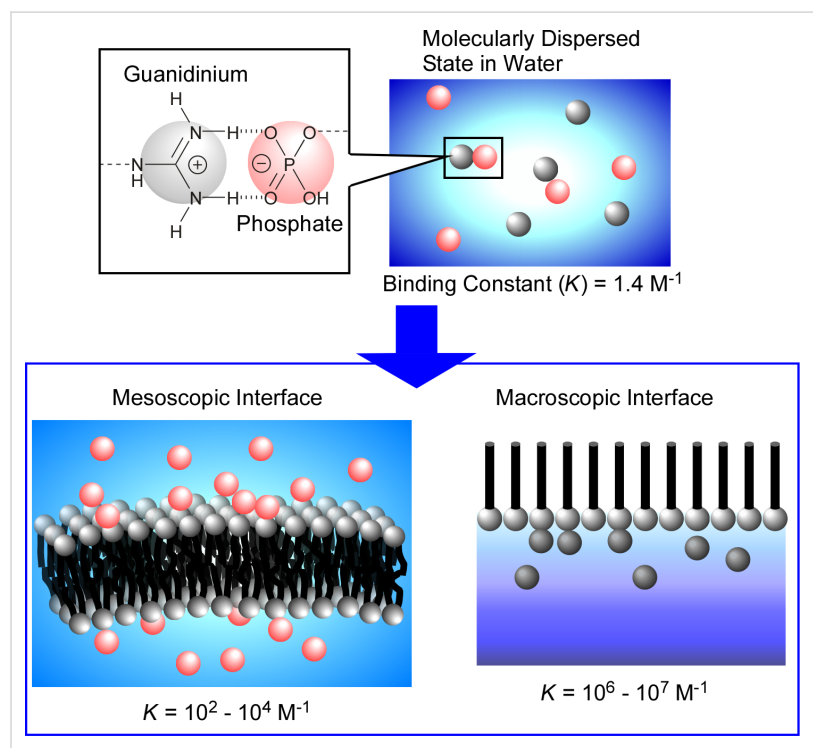

Figure 3: Systematic studies on binding constants for phosphate and guanidinium in different aqueous environments: $1.4 \mathrm{M}^{-1}$ dispersed in water; $10^{2}$ to $10^{4} \mathrm{M}^{-1}$ at disorganized mesoscopic interfaces; $10^{6}$ to $10^{7} \mathrm{M}^{-1}$ at the macroscopic air-water interface. Adapted with permission from [144], copyright 2019 American Chemical Society.

Mechanisms enhancing the molecular interaction at the air-water interface were investigated through quantum chemical approaches [159-161]. As simply illustrated in Figure 4, simplified recognition-pair structures of phosphate and guanidinium were placed at a model interface of two phases with different dielectric constants of 2 (lipid phase) and 80 (water 


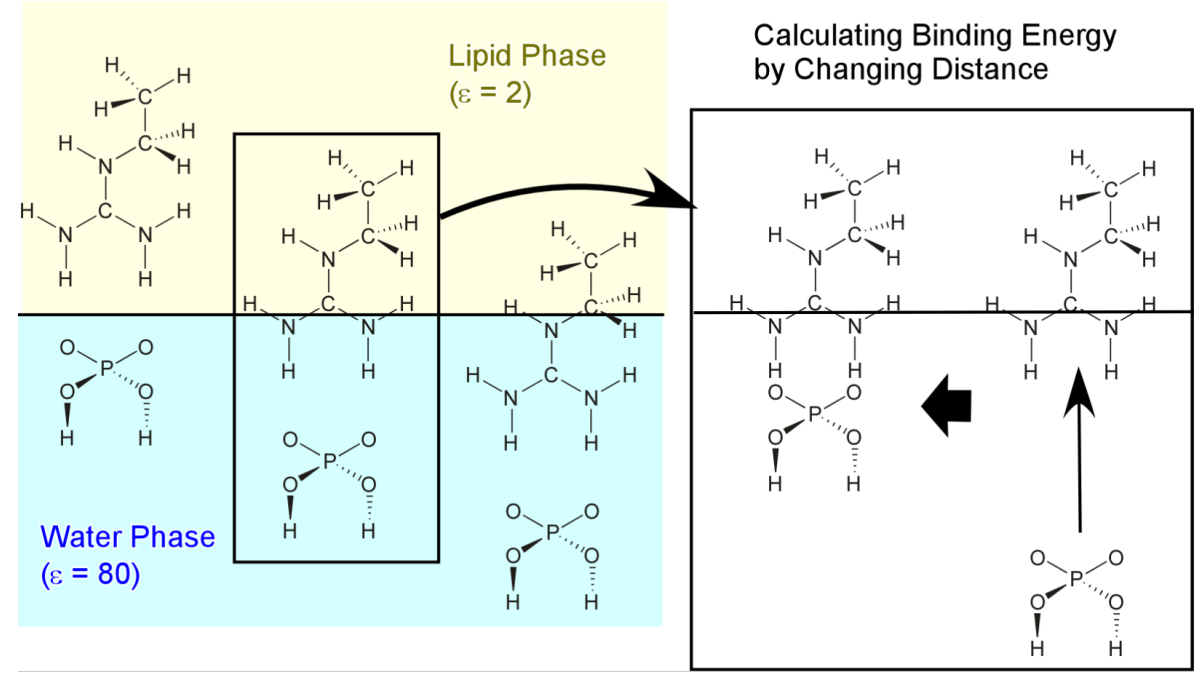

Figure 4: A model for calculations of the binding constant between guanidinium and phosphate at the air-water interface where the pair structures of phosphate and guanidinium are placed in a model of two phases with different dielectric constants of 2 (lipid phase) and 80 (water phase). The binding energy and binding constant was calculated while changing distance between guanidinium and phosphate.

phase). By fixing the position of the guanidinium moiety at the interface and changing the relative location of the phosphate functional group, the recognition energy was monitored as a function of the relative location. The most stable relative distance was estimated from the energy minimum in the energy diagram, and the binding energies and binding constants were calculated at those interfacial positions. A series of calculations revealed that large binding constants can be obtained when the binding site locates in the phase of the lower dielectric constant. In contrast, when the binding site was located to be deep in the phase of the higher dielectric constant, the binding constants were calculated to decrease significantly. Interestingly, sufficiently high binding constants were confirmed even when the hydrogen bonding sites were exposed to the high-dielectric medium at the very vicinity of the low-dielectric medium. These simulations hint at the mechanism of enhanced molecular recognition at these interfaces. The non-polar phase greatly contributes to enhance molecular recognition.

These facts may answer the question of biological molecular recognition in aqueous media, in which hydrogen bonding plays an essential role in realizing those highly sophisticated systems [162]. Molecular recognitions in biological systems occur mostly at interfaces including cell membrane surfaces, inner surfaces of receptor pockets in enzymes, and macromolecular interfaces of DNA. We expect materials nanoarchitectonics with features of enhanced molecular interactions to create lowdimensional materials at interfaces of two phases with different dielectric natures.
Another distinctive characteristic of liquid interfaces is the anisotropic environment regarding molecular motion. Certain degrees of motional freedom exist along the interfacial plane, which can be deformed at the macroscopic level (compression, expansion, and bending). In contrast, molecular motion is virtually inhibited in the vertical direction. Therefore, two significantly different scales of motion, macroscopic lateral motion and nanoscopic vertical motion, are connected at liquid interfaces [163-166]. For example, motion and function of molecular machines and molecular receptors in monolayers at the air-water interface can be controlled by macroscopic lateral motion such as mechanical compression and expansion of the monolayers. Macroscopic mechanical deformation of the interfacial media at the scale of centimetres or metres can regulate nanometre-scale conformational changes of the molecular machines, for instance, to capture and release guest molecules $[167,168]$, to rotate of molecular rotors $[169,170]$, to open and close molecular pliers [171,172], or in indicator displacement assays of glucose based on fluorescence resonance energy transfer [173]. Subtle conformational changes of molecular receptors at the air-water interface results in a change of the chiral selectivity towards aqueous amino acids [174,175], or of the optimum guest structure from thymine to uracil derivatives [176,177]. Regulation of molecular interaction at liquid interfaces yields a novel concept for the molecular tuning of functions [178-180]. This is a new concept beyond the following well-known important concepts: the 1st generation of molecular recognition at the most stable state (basics for supramolecular chemistry, Nobel prize in 1987 [181-183]); the 2nd genera- 
tion molecular controls based on external stimuli switching [184-188] (basics for molecular machines, Nobel prize in 2016 [189-191]). The anisotropic dynamics at liquid interfaces described above are expected to play a crucial role in the production of low-dimensional materials and systems.

\subsection{Two-dimensional molecular patterning and production of low-dimensional materials}

Enhanced molecular interaction and two-dimensionally confined motion at liquid interfaces are advantageous for the fabrication of two-dimensional patterned structures with high structural precision $[192,193]$. In the case exemplified in Figure 5, flavin adenine dinucleotide (FAD) was dissolved in an aqueous subphase [194,195]. FAD can bind specifically to two monolayer components, a guanidinium lipid or an orotate lipid. These molecules bind site-specifically to the phosphate moieties or the adenosine part, respectively. Lateral compression of the complexed monolayer finally results in two-dimensional regular molecular patterns. The difference between the molecular lengths of the guanidinium/phosphate and orotate/adenosine pairs yields regular dip patterns with sub-nanometre precision. Similar methodologies, i.e., crystallinity controlled two-dimensional patterns based on guanidinium/carboxylate molecular recognition [196] and the two-dimensional assembly of onedimensional supramolecular polymers formed between alkylated melamine and aqueous barbiturate [197] have been also accomplished.

Oishi and co-workers utilized the balance between two competitive interactions, the phase separation of fluorocarbons and hydrocarbons and the attractive interaction between guanidiuium and carboxylate, to fabricate nanoscopic domains within a two-dimensional mixture of hydrocarbon guanidinium and fluorocarbon carboxylic acid [198]. The domain sizes can be tuned by altering the mixing ratio of the two components. In a recent review article by Krafft and co-workers [199], the formation of surface nanodomains and their hierarchical organization with higher complexity with semi-fluorinated alkanes and

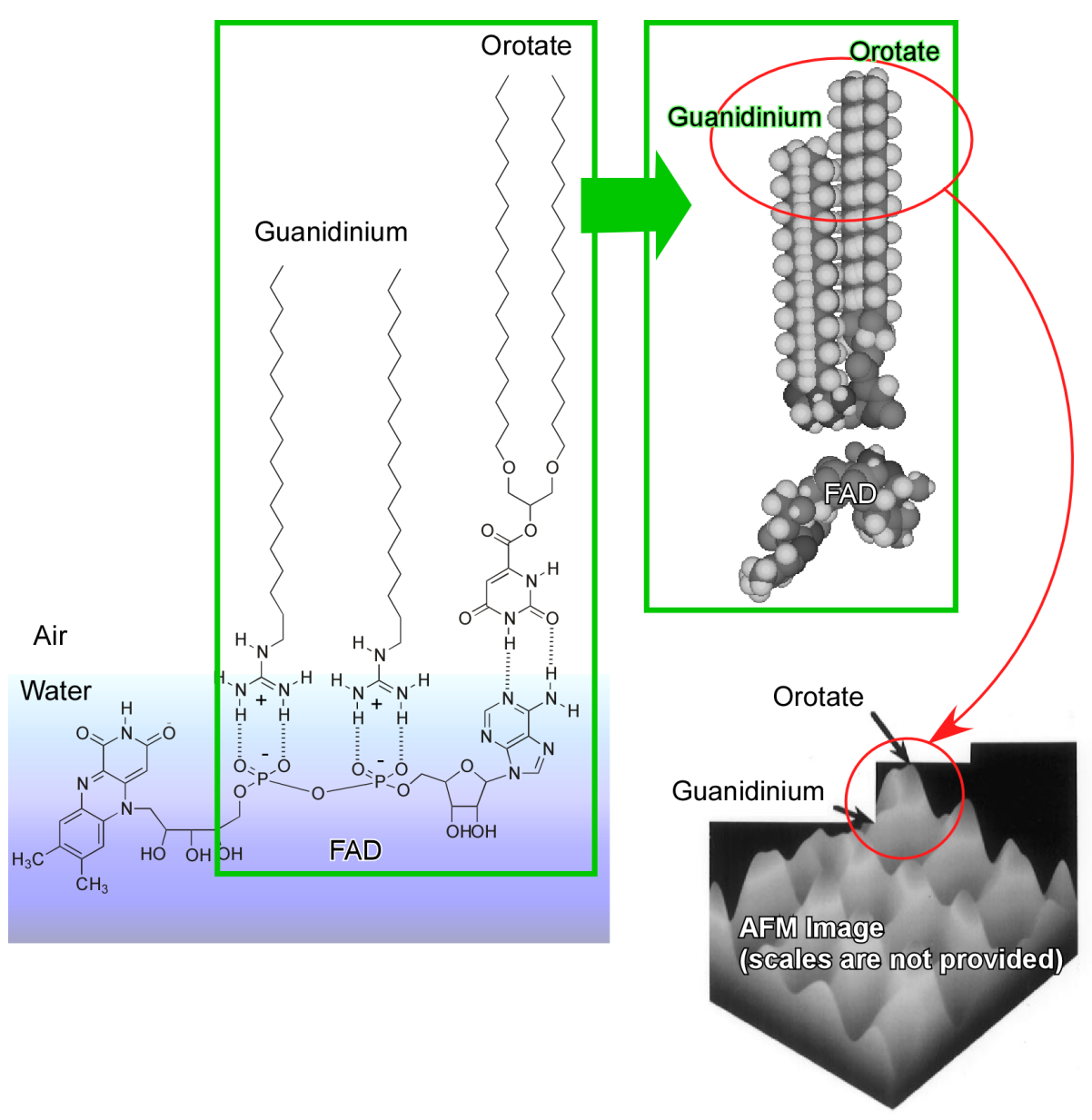

Figure 5: Formation of two-dimensional patterned structures using flavin adenine dinucleotide (FAD), which can bind site-specifically to two monolayer components, a guanidinium lipid or an orotate lipid, with the phosphate moieties and adenosine part, respectively. Adapted with permission from [195], copyright 1997 American Chemical Society. 
related molecules (molecules consisting of two blocks, a fluorocarbon block and a hydrocarbon block, in a single chain) at the air-water interface is discussed. They expect possible applications of these two-dimensional nanodomains in sensors, nanoelectronics and nanophotonics.

Pellerin, Bazuin, and co-workers investigated the mechanisms of formation and transformation of zero-dimensional structures within two-dimensional media (dot-dispersed monolayers of block copolymers) [200]. Self-assembled monolayers of polystyrene- $b$-poly(4-vinylpyridine) and its supramolecular complex with 3-n-pentadecylphenol at the air-water interface alter their assembly patterns from hexagonal to squared upon applying lateral pressure. The transition is caused by the entropically driven molecular folding of the poly(4-vinylpyridine) moieties, in which the polymer transforms from a two-dimensional motif to a three-dimensional motif. The proposed mechanism might be generalized for zero-dimensional dot-dispersed monolayers of block-copolymers. Wen and co-workers reported the drastic modification of two-dimensionally patterned Langmuir-Blodgett (LB) films of polystyrene- $b$-poly(2vinylpyridine) transferred from the air-water interface through acetone vapour annealing [201]. Complicated morphology shifts such as swelling, coalescing of aggregates, bicontinuous pattern formation, one-dimensional droplet formation, and the periodic evolution of the droplets were observed.
Mori et al. reported the formation of two-dimensional arrays of disk-shaped nano-assemblies at the air-water interface yielding a monolayer that was successively transferred onto solid surfaces via the contacting method (Figure 6) [202]. Unlike twodimensional molecular patterning though molecular recognition, which has been described in the previous parts, a rather ambiguous interaction between amphiphilic triimide with three alkyl chains, a monolayer component, and 1,4,7,10-tetraazacyclododecane (cyclen), a subphase template, was used to regulate the formation of hydrogen bonds between the imide functional groups as hydrogen-bond acceptors and the secondary amine moieties of cyclen as hydrogen-bond donors. The twodimensional quick dewetting process on a Langmuir-Schaefertype surface can induce a good dispersion of nanodisks. Although the heights of nanodisks reported so far are within a narrow range between 2.6 and $2.9 \mathrm{~nm}$, their diameters can widely range from 46 to $73 \mathrm{~nm}$ depending on their lateral surface pressure at the air-water interface. The fabricated array structures of nanodisks can be also transferred to metal surfaces such as platinum surfaces. The examples demonstrated that the combination of rather ambiguous molecular interactions and transfer processes can create precise patterns, which are one of the main concept of nanoarchitectonics.

Small gelation molecules often form one-dimensional assembled structures [203-207]. The inner structures of these one-

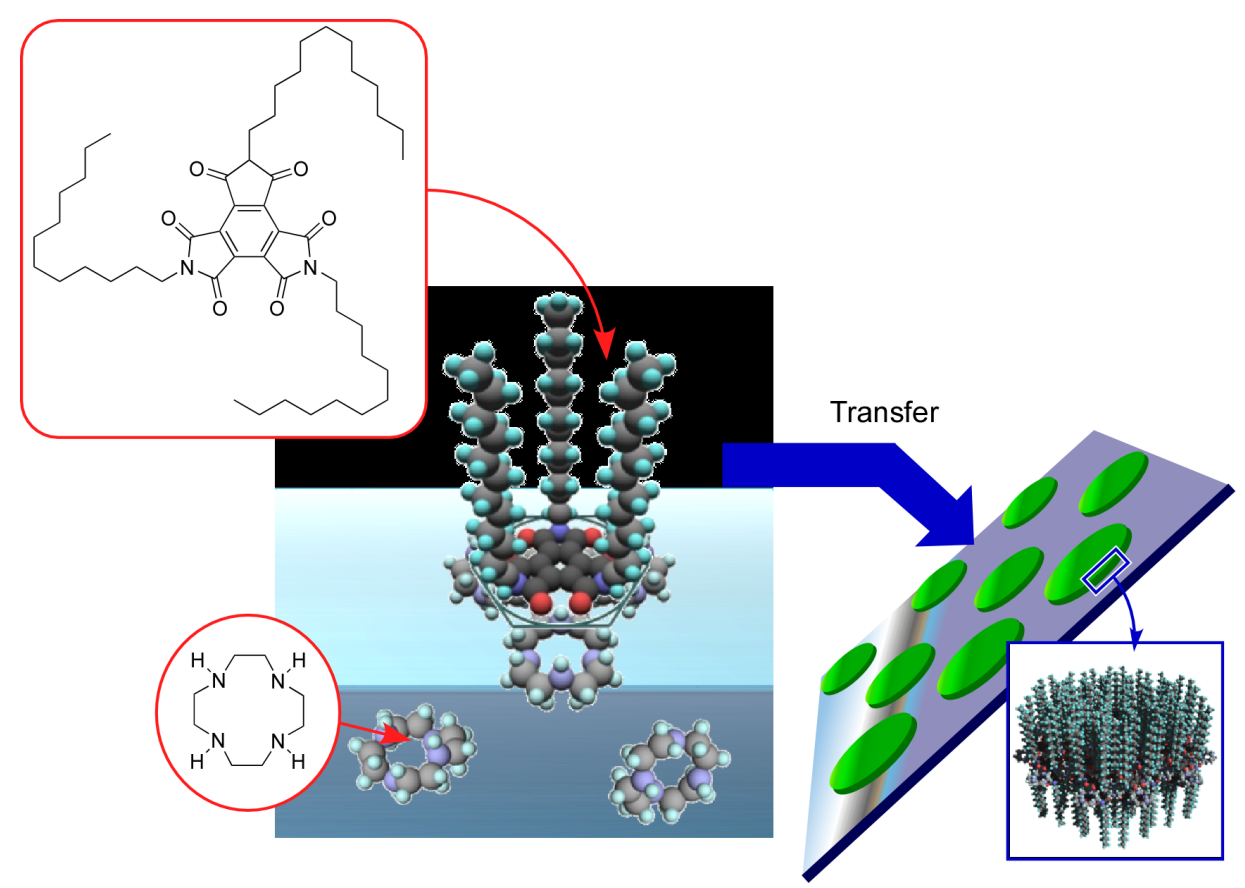

Figure 6: Formation of two-dimensional arrays of nanodisk-like assemblies via touching transfer of a monolayer of amphiphilic tri- $n$-dodecylmellitic triimide with three alkyl chains as a monolayer component and 1,4,7,10-tetraazacyclododecane (cyclen) as a subphase template. Adapted from [75], copyright 2019 The Authors. 
dimensional objects can be significantly altered through the surrounding media such as organic solutions and the air-water interface. Sakakibara et al. investigated the morphological change of one-dimensional assemblies of oligo( $p$-phenylenevinylene) induced by different media (Figure 7) [208]. In entangled fibre structures, formed in toluene solution and successively transferred on a solid surface by drop-casting, the long axis of oligo( $p$-phenylenevinylene) molecules is arranged perpendicularly to the substrate. Intra-fiber energy transfer efficiently occurs in the entangled nanofibers. Long-range excitation energy transfers are advantageous for excitation energy transfer. In contrast, the oligo( $p$-phenylenevinylene) molecular units are oriented in parallel to the long axis of the aligned rods that were formed at the air-water interface from its homogeneous solution in chloroform. The excitation preferences between inter- and intra-fiber can be altered by controlling the arrangement of the aligned rods. In environments of closely packed nanorods (when the inter-rod distance was less than

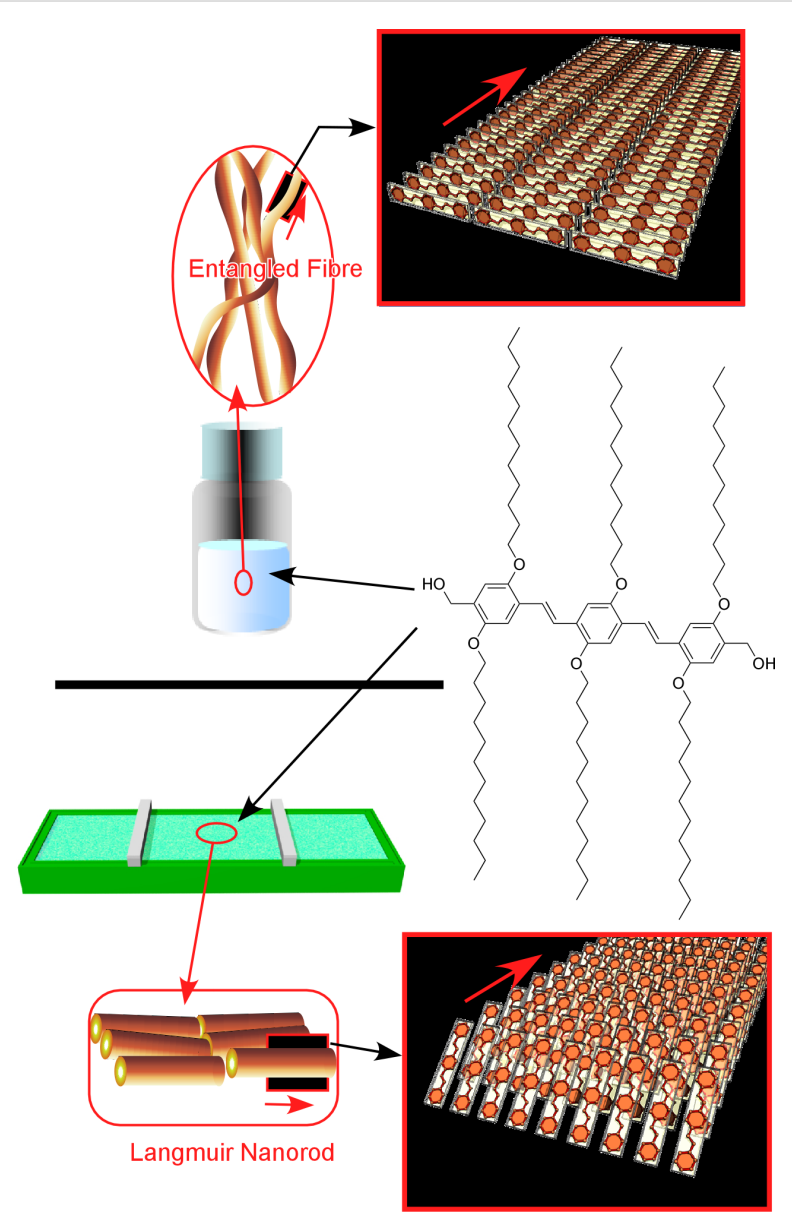

Figure 7: Difference of one-dimensional assemblies of an oligo( $p$ phenylenevinylene) derivative formed in different media: (top) entangled fibre structures formed in toluene solution and drop-cast on a solid surface; (bottom) aligned rods formed at the air-water interface. Adapted from [75], copyright 2019 The Authors. ca. $70 \mathrm{~nm}$ ), enhanced excitation transfer was observed, indicating that fluorescence would be efficiently enhanced within well-aligned nanorods prepared at the air-water interface.

Inorganic low-dimensional nanomaterials often exhibit interesting properties [209-215]. Such materials can be also nano-engineered at liquid interfaces. Niederberger and co-workers successfully fabricated two-dimensionally aligned arrays of onedimensional $\mathrm{W}_{18} \mathrm{O}_{49}$ nanowires and used them for $\mathrm{H}_{2}$-sensing at room temperature [216]. The diameters of the used nanowires are less than $2 \mathrm{~nm}$ and their aspect ratios exceed 100. The synthesized nanowires are dispersible in organic solvents and can be fabricated in large-area aligned arrays at the air-water interface. The films were transferred onto $\mathrm{Si} / \mathrm{SiO}_{2}$ substrates patterned with platinum interdigitated electrodes. An excellent sensor capability for $\mathrm{H}_{2}$ gas in humid air at room temperature was observed for a film of 10 layers of the aligned one-dimensional $\mathrm{W}_{18} \mathrm{O}_{49}$ nanowires. Various additional techniques to fabricate two-dimensional structures have been proposed. Advincula and co-workers demonstrated two-dimensional co-patterned structures of carbazole-based conductive polymers and gold by nanosphere lithography [217]. Huang and co-workers proposed a high-yield LB method for nanoparticle films through electrospray techniques to significantly reduce the spreading of droplets and used a subphase-miscible solvent [218]. The modified method may become a powerful method to fabricate two-dimensional thin films of zero-dimensional nanoparticles at liquid interface.

The lateral degree of motional freedom of the liquid interfaces can promote associations of molecules and materials for the fabrication of two-dimensionally structures. As depicted in Figure 8, Yonamine et al. successfully demonstrated the onedimensional supramolecular polymerization of DNA origami pieces upon repeated mechanical compression and expansion of the two-dimensional air-water interface [219]. The used DNA origami pieces had a rectangle shape with $90 \times 65 \mathrm{~nm}^{2}$, according to theoretical calculations, and were complexed with counter-cationic lipids to be soluble in organic solvents. The resulting organic solution of the DNA origami pieces was then spread on the air-water interface to form a Langmuir monolayer. Although the spread DNA origami pieces initially remained in the monomer form, the repeated mechanical compression and expansion of the Langmuir monolayer induced the interconnection of the rectangle pieces into onedimensional polymer motifs. The origami-origami connections were formed only at the shorter sides of the rectangle pieces where dangling DNA chains remained. The enhanced capability of hydrogen-bond formation at the air-water interface resulted in one-dimensional supramolecular polymers through inter-piece connections at the specific sides. Interestingly, 


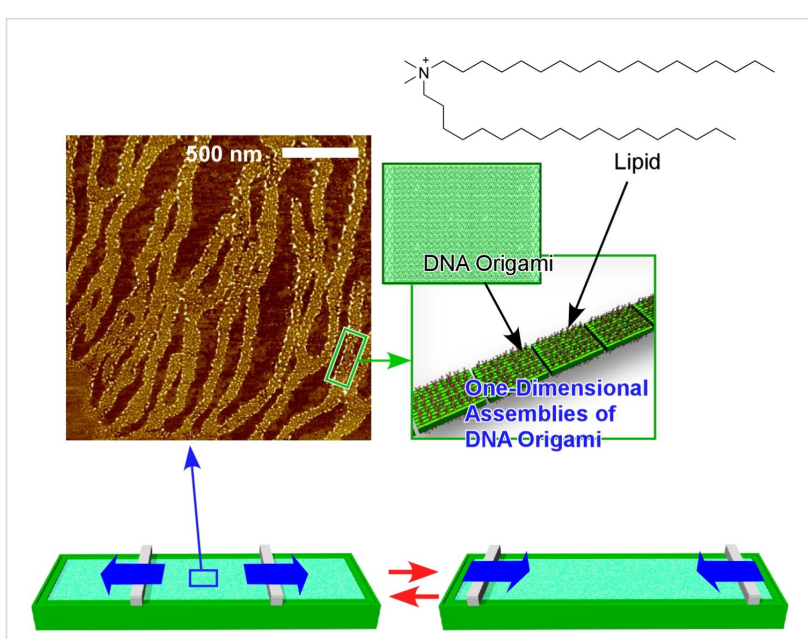

Figure 8: Formation of one-dimensional supramolecular polymerization of DNA origami pieces upon repeated mechanical compressions and expansions of two-dimensional air-water interface. An AFM image was reprinted with permission from [144], copyright 2019 American Chemical Society.

dynamic motion is indispensable for the formation of these supramolecular polymers of DNA origami. A simple application of high pressure is not enough to obtain supramolecular polymerization of DNA origami pieces at the air-water interface.

\section{Interfacial nanoarchitectonics for MOF and $\mathrm{COF}$}

Interfaces are attractive platforms to synthesize two-dimensional materials. The recent developments of synthetic twodimensional crystalline polymers (2DCPs), such as two-dimensional metal-organic frameworks (MOFs) and two-dimensional covalent organic frameworks (COFs), have unveiled their intriguing chemistry and properties, and have shown their potential for wide-ranging applications, such as electronics, sensing, catalysis, separation, and energy storage and conversion. However, most reported two-dimensional MOFs and COFs have been synthesised as powders, which are not easily processed into more useful forms due to their nature as crosslinked polymers. Thus, their adaption for technological applications is still challenging. Recently, liquid interfaces have been considered to be useful platforms to form thin 2DCP films, and the number of examples showing interfacially grown $2 \mathrm{DCP}$ films for potential applications is increasing [220].

The air-water interface is the most commonly used liquid interface to grow 2DCP films. In 2002, Culp et al. reported a reaction of a Langmuir monolayer of an amphiphilic pentacyanoferrate complex with $\mathrm{Ni}^{2+}$ ions from the subphase (Figure 9) [221]. This reaction resulted in the formation of a two-dimensional iron-nickel cyanide-bridged network at the air-water interface. A small amount of the amphiphilic pentacyanoferrate complex

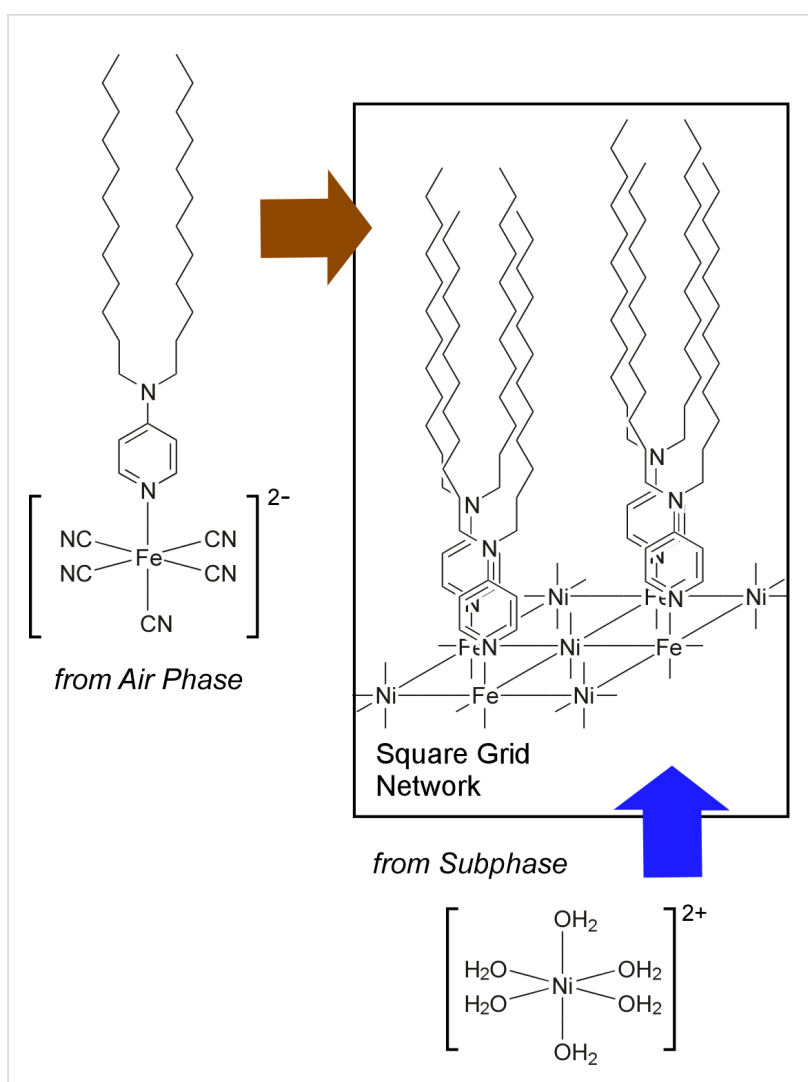

Figure 9: Formation of a two-dimensional iron-nickel cyanide-bridged network at the air-water interface through reaction of a Langmuir monolayer of an amphiphilic pentacyanoferrate complex with $\mathrm{Ni}^{2+}$ ions from the subphase.

monomer was spread from a chloroform solution to form a monolayer in a LB trough, and was subsequently connected by introducing an aqueous solution of nickel nitrate into the water phase, yielding a monolayer sheet of the two-dimensional nickel-iron cyanide grid network. Characterizations of the extended network by X-ray photoelectron spectroscopy (XPS), FTIR spectroscopy, SQUID magnetometry, X-ray absorption fine structure (XAFS), and grazing incidence synchrotron X-ray diffraction (GIXD) revealed a face-centred square grid structure with an average domain size of $3600 \AA^{2}$.

Makiura et al. employed a similar method to form multilayers of an oriented porphyrin-based MOF film on top of substrates by repeating transfer and washing of interfacially grown MOF layers (Figure 10) [222]. Interestingly, the proposed structural model incorporates metal-coordinated pyridine molecules projected from the two-dimensional sheets that allow each further layer to dock in a highly ordered interdigitated manner in the growth of multilayer structures. $\mathrm{Ni}_{3}(2,3,6,7,10,11$-hexaiminotriphenylene $)_{2}, \mathrm{Ni}_{3}(\mathrm{HITP})_{2}$, is a conjugated MOF films of which were prepared by interfacial polymerization at the air-water interface. Wu et al. prepared a $\mathrm{Ni}_{3}(\mathrm{HITP})_{2} \mathrm{MOF}$ film 


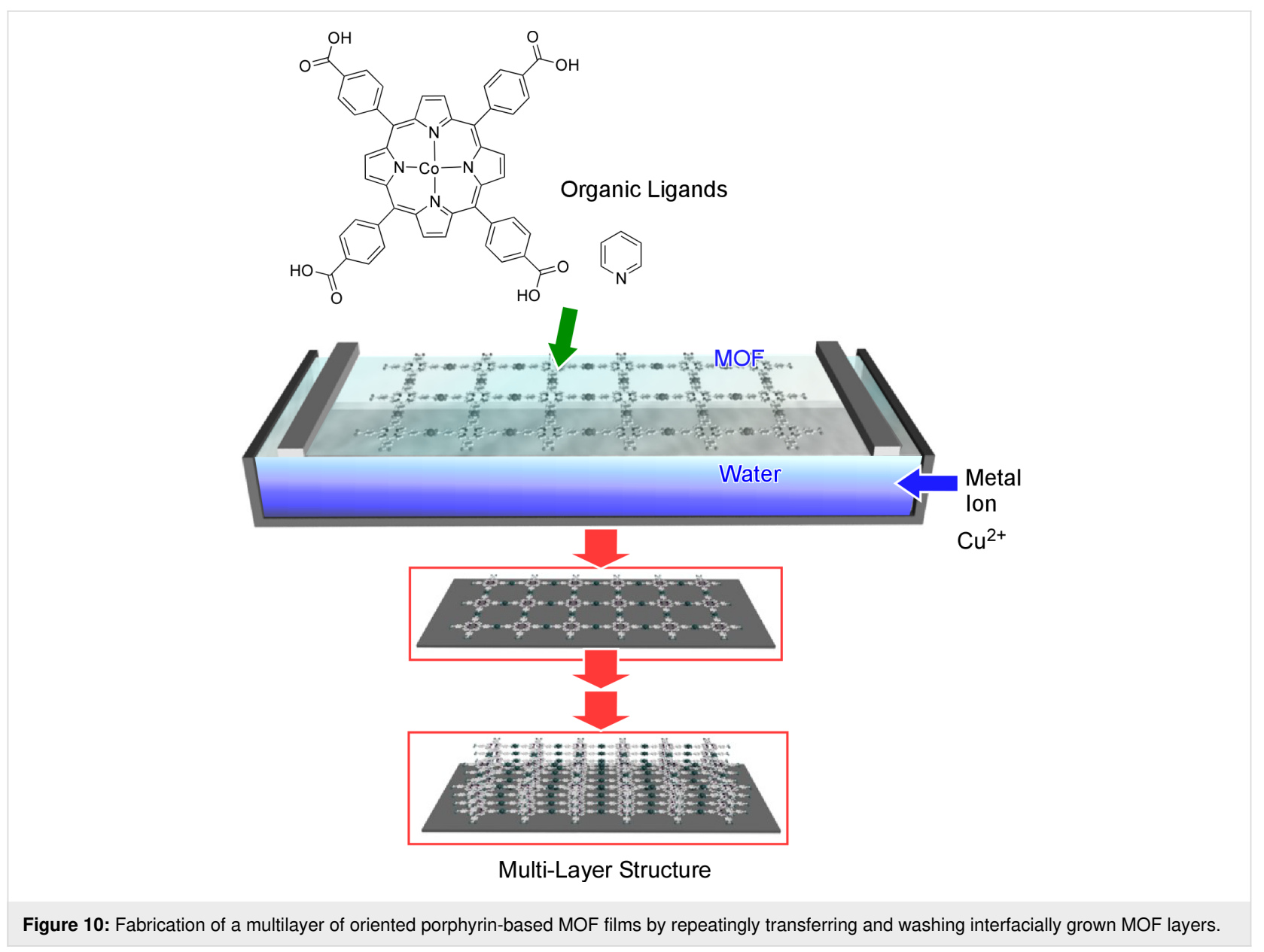

and incorporated the resulting film into field-effect transistor (FET) devices, exhibiting p-type semiconductive behaviour, distinguishable on/off ratios, and excellent field-effect hole mobility values as high as $48.6 \mathrm{~cm}^{2} \cdot \mathrm{V}^{-1} \cdot \mathrm{s}^{-1}$ [223].

A COF film interfacially grown at a liquid-gas interface was also incorporated into a FET device and examined. Feldblyum et al. found an imine-linked COF film growing at the interface of air and a $\mathrm{N}, \mathrm{N}$-dimethylformamide (DMF) solution of $\mathrm{COF}$ precursors consisting of benzothiophene and triphenylamine moieties [224]. The interfacially grown film was transferred onto Si substrates in order to fabricate FET devices. The COFfilm FET device also exhibited p-type behaviour, an average mobility of $3.010^{-6} \mathrm{~cm}^{2} \cdot \mathrm{V}^{-1} \cdot \mathrm{s}^{-1}$, and an on/off ratio of 850 . Imine-linked COF films were also fabricated with the common interfacial polymerization method using LB troughs. Dai et al. newly designed a trisubstituted amine monomer bearing three $n$-hexyl groups [225]. These aliphatic chains are helpful to fix the orientation of the amine monomer when deposited on an air-water interface together with a dialdehyde monomer. The monomers compressed with an LB trough were polymerized with acetic acid as catalyst in the water phase.
Liquid-liquid interfaces are another class of interfaces used for the interfacial polymerization of 2DCPs. Because of the relatively dynamic nature of two liquids, the liquid-liquid interfaces are, in general, less well-defined than liquid-gas interfaces. Hence, the interfacial polymerizations tend to afford thicker films [220]. $\pi$-conjugated nickel bis(dithiolene) complex nanosheets reported by Kambe and co-workers [226] were one of the first representative examples for interfacially polymerized MOF films at the liquid-liquid interface. Two immiscible phases of water and dichloromethane spatially segregate nickel acetate, a metal node precursor, from benzenehexathiol (BHT, a coordinating linker) and confine the MOF formation to the liquid interface. The interfacially grown BHT-Ni network film of 1-2 $\mu \mathrm{m}$ thickness exhibited X-ray diffraction patterns corresponding to a crystalline network structure.

Takada et al. adopted a similar technique to form electrochromic bis(terpyridine)metal complex nanosheets (Figure 11) [227]. The demonstrated network structures are connected by the coordination of terpyridine moieties to either cobalt or iron ions, and the synthesized films change their colour depending on the oxidation levels of the cobalt and iron 
ions. The colours of those MOF films can be modulated through electrochemical processes.

The interfacial formation of COFs at the liquid-liquid interfaces is more complicated because of the necessity of watersoluble COF precursors. Sahabudeen et al. have overcome this issue by using a hydrophilic dialdehyde monomer, 2,5-dihydroxyterephthalaldehyde (DHTPA) [228]. DHTPA was dissolved in water, and the resulted aqueous solution was layered on top of a chloroform solution of a tetra-substituted amine monomer containing porphyrin. The segregation of the monomers confined the imine formation to the interface and yielded wafer-size multilayer imine-linked COF films. The films grown from the amine monomer containing cobalt porphyrin exhibited catalytic activity for the electrochemical hydrogen generation from water. Dey et al. have dissolved one COF monomer into the aqueous phase by forming amine salts (Figure 12) [229]. Various multi-amino-substituted monomers were treated with $p$-toluene sulfonic acid (PTSA) forming [amine-PTSA] salts, and dissolved into aqueous phases. Each aqueous solution was layered on a dichloromethane solution containing 1,3,5triformylphloroglucinol ( $\mathrm{Tp}$ ), an aldehyde-derivative COF monomer, yielding large COF films of sub-100 nm thickness. The prepared materials were capable of selective permeation.

In contrast to the two previous reports in which one of the COF monomers was dissolved into the aqueous phase, Matsumoto et al. confined the polymerization to the interface by segregating the catalyst from the COF monomers (Figure 13) [230]. Scandium triflate, one of the catalysts forming imine-linked COFs [231] in the aqueous phase was isolated from both amine and aldehyde COF monomers dissolved into an organic phase. The
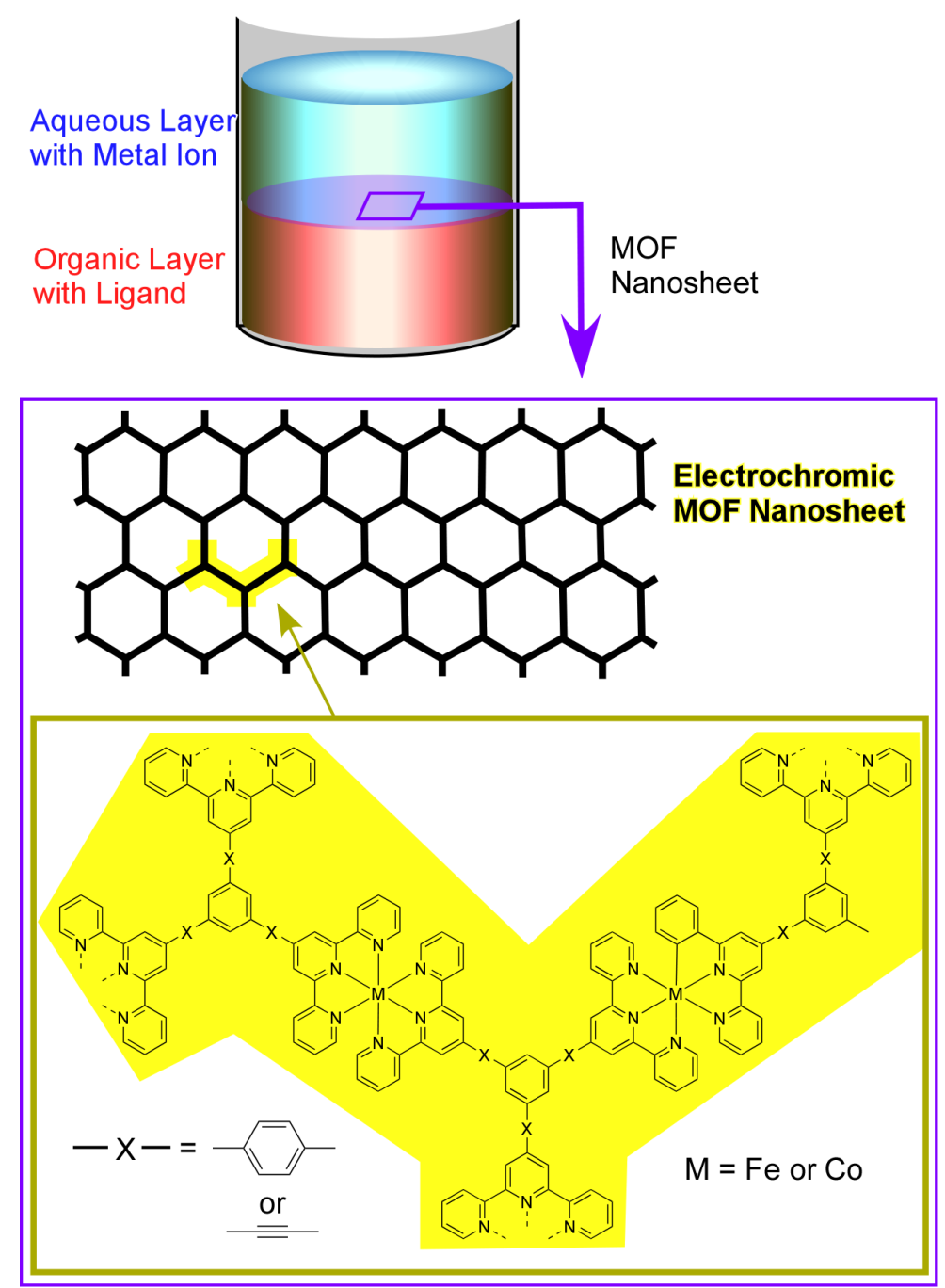

Figure 11: Electrochromic bis(terpyridine)metal complex MOF nanosheets formed through coordination of terpyridine moieties to either cobalt or iron ions. The synthesized films change their colour depending on the oxidation levels of the cobalt and iron ions. 


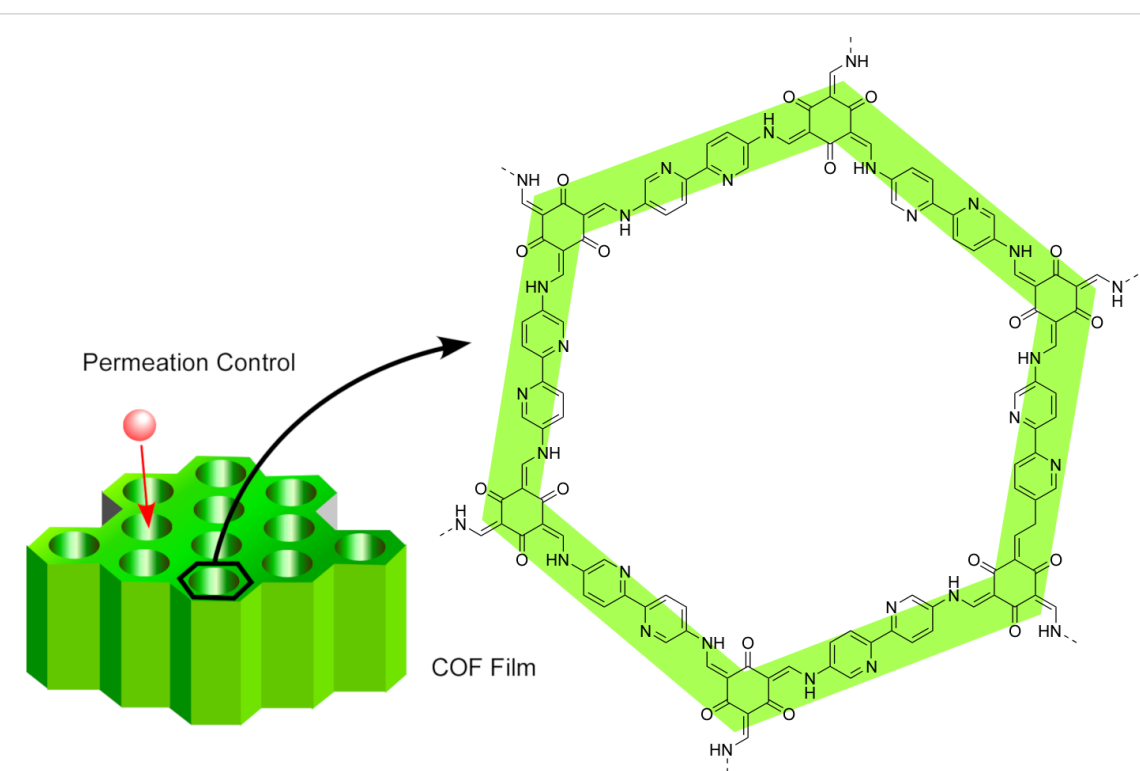

Figure 12: Aqueous solutions of multi-amino-substituted monomers with $p$-toluene sulfonic acid were layered on a dichloromethane solution containing 1,3,5-triformylphloroglucinol to yield large COF films of sub-100 $\mathrm{nm}$ thickness.

two phases in contact with each other induced the COF formation at the interface, forming large-area, continuous COF films (several square centimetres). Depending on the monomer concentrations, the film thickness was tuned from $100 \mu \mathrm{m}$ to a few nanometres. The COF films made from the methods reported by Dey et al. and Matsumoto et al. were separately examined as separation membranes and exhibited high rejections of water pollutant surrogates from water [229-231]. Considering the high tuning capability of pore-size and functional groups decorating the inner pores of COFs, the separation membranes made out of COFs are promising for water purification technologies including desalination [232].

Interfacial polymerization at liquid interfaces is an already industrialized technique to produce conventional cross-linked polymer films/membranes. Interfacial polymerization of $2 \mathrm{DCP}$ films still remains in its infant stage in terms of controlling crystallinity, domain sizes, and generalities. However, the developments on interfacial polymerization of 2DCPs at liquid interfaces will be an important breakthrough for industrializing 2DCP materials.

\section{Interfacial nanoarchitectonics for nanocarbon materials}

\subsection{Bottom-up production of nanocarbon materials}

Low-dimensional carbon materials, such as carbon nanotubes and graphene derivatives, are now widely used especially in energy and environmental research fields [233]. A lot of attention has also been paid on the creation of novel nanocarbon materials from molecular units and structurally well-defined assemblies from nanocarbon units. Regarding the latter, liquid interfaces often provide important anisotropic fabrication media to synthesize novel types of low-dimensional carbon materials.

Recently, Mori et al. successfully demonstrated the fabrication of two-dimensional nanocarbon films from a designed molecular unit, the carbon nanoring molecule $\left(9,9^{\prime}, 10,10^{\prime}\right.$-tetrabutoxycyclo[6]paraphenylene[2]-3,6-phenanthrenylene), by using newly developed vortex LB method at a liquid interface with dynamic flow (Figure 14) [234]. For this bottom-up fabrication, the chloroform solution of the carbon nanoring was dripped at the air-water interface under rotating vortex flow. Appropriate flow rates yielded two-dimensional films of the carbon nanoring molecule with uniform thickness of a few nanometres. The monolayer films were transferred from the water surface to a solid substrate by hand. Further heat treatment under inert gas atmosphere led to the formation of uniform two-dimensional nanocarbon films, so-called carbon nanosheets, with ca. $10 \mathrm{~nm}$ thickness with dispersed nanopore structural motifs. The electrical conductivity of the transferred film was significantly increased after the thermal carbonization process. Nitrogendoping was carried out simply by mixing nitrogen-containing compounds such as pyridine into the original solution of the carbon nanoring molecule. The prepared nitrogen-doped carbon nanosheets exhibited a higher electrical conductivity than the non-doped ones did. It should be noted that these nanomaterial fabrications can be conducted by using solely very common apparatuses such as beaker, stirrer, and tweezers. Therefore, the proposed method can be more generalized and extended even to industrial applications. 


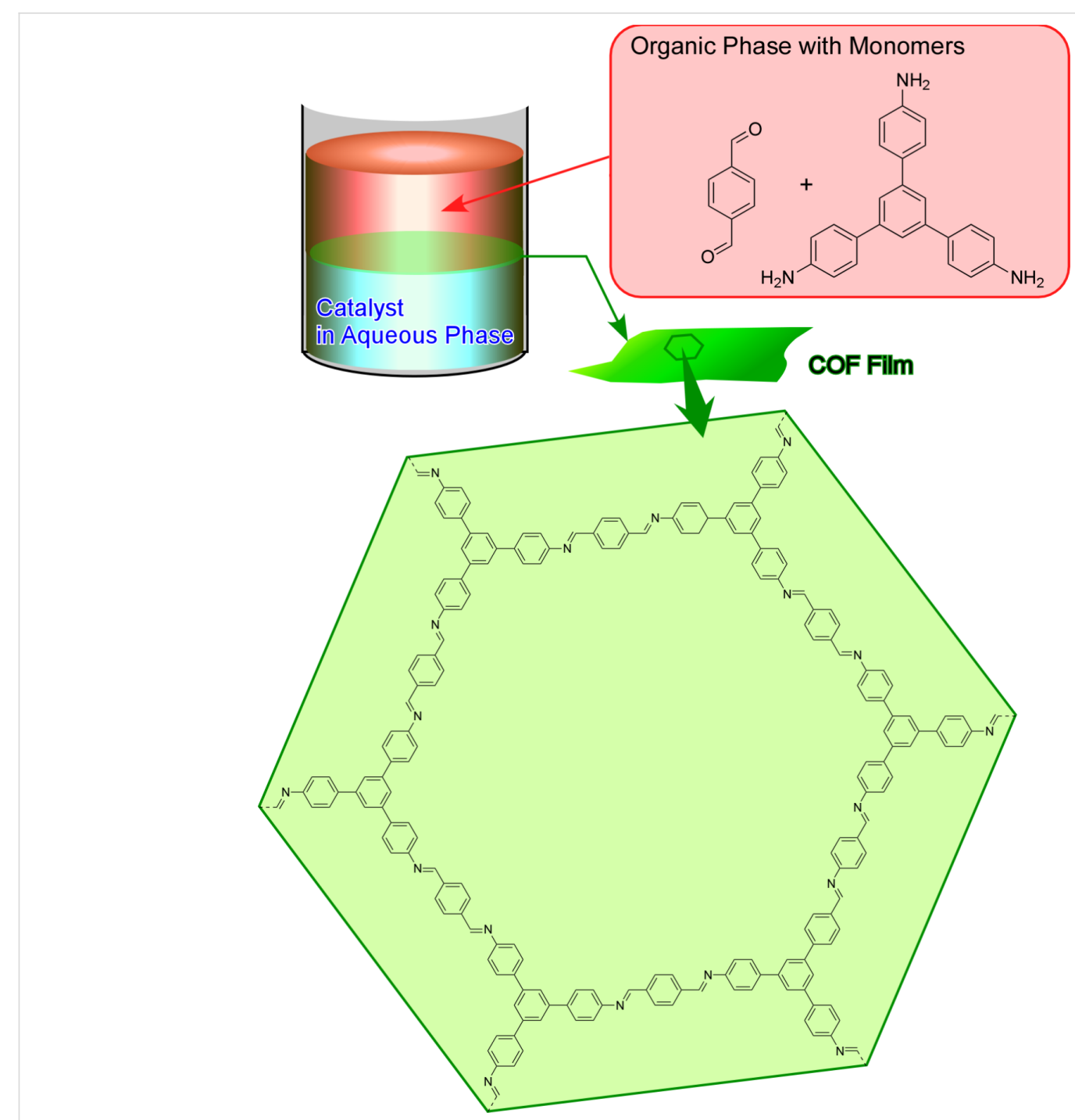

Figure 13: Confined polymerization at the interface by spatially segregating a catalyst from the COF monomers. The formation of imine at the interface of aqueous and organic layer yielded large-area, continuous COF films.

For the bottom-up fabrication of nanocarbon materials through self-assembly processes, the use of fullerene (especially, $\mathrm{C}_{60}$ ) molecules as assembling components are both technically and scientifically attractive [235]. In addition to the technical importance of fullerene in many applications including physical devices and biomedical usages, assembly processes from completely symmetrical zero-dimensional objects with single elemental composition (carbon) are an intriguing fundamental topic in supramolecular chemistry [236]. Miyazawa and co-workers initiated a simple but highly useful method, i.e., liquid-liquid interfacial precipitation, to fabricate fullerene assemblies (crystals) with various morphologies (Figure 15) [237-239]. Fullerene molecules, such as $\mathrm{C}_{60}$ and $\mathrm{C}_{70}$, are dissolved in a liquid phase (good solvent) that contacts an immiscible liquid phase in which the molecules are poorly soluble (poor solvent). The formation of crystalline assemblies of ful- lerene molecules is induced by supersaturation at the liquid-liquid interface. For example, $\mathrm{C}_{60}$ rods or needles can be obtained at the interface between a saturated solution of $\mathrm{C}_{60}$ in toluene and isopropyl alcohol as poor solvent.

\subsection{One-dimensional fullerene assembly materials}

Shrestha and co-workers have extended the research on dimensionally controlled assemblies of fullerene molecules through liquid-liquid interfacial precipitation [240]. For example, the conversion from one-dimensional structures to three-dimensional morphologies of $\mathrm{C}_{60}$ rods and tubes was carried out via a surfactant-assisted process in liquid-liquid interfacial precipitation [241]. At the interface between butanol and benzene, $\mathrm{C}_{60}$ typically assembles into one-dimensional superstructures (rods and tubes). However, by adding surfactants to those interfacial systems, the morphology of the assemblies can be altered to 


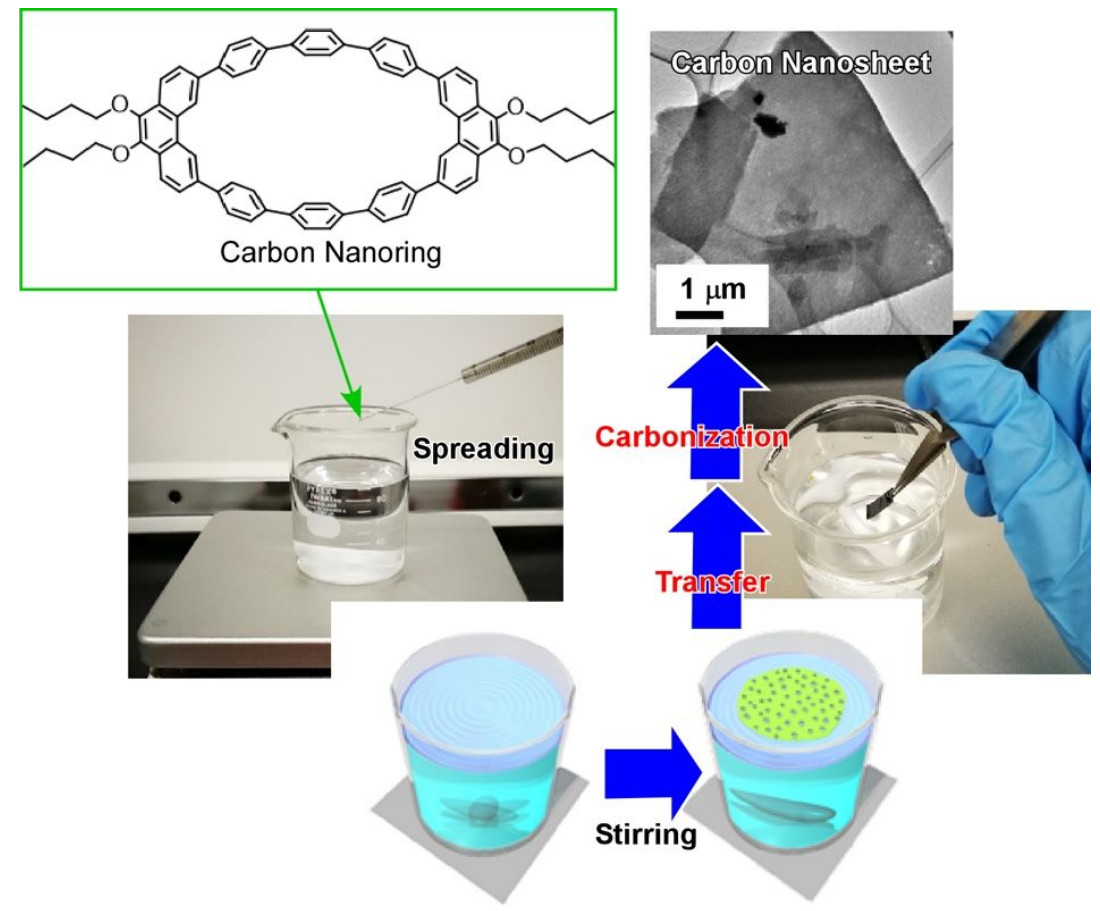

Figure 14: Fabrication of two-dimensional nanocarbon films from a carbon nanoring molecule $\left(9,9^{\prime}, 10,10^{\prime}\right.$-tetrabutoxycyclo[6]paraphenylene[2]-3,6phenanthrene) via a newly developed vortex LB method at a liquid interface with dynamic flow followed by heat treatment under inert gas atmosphere. Both photographs were reproduced with permission from [68], copyright 2019 The Royal Society of Chemistry; the TEM image was reproduced from [75], copyright The authors.

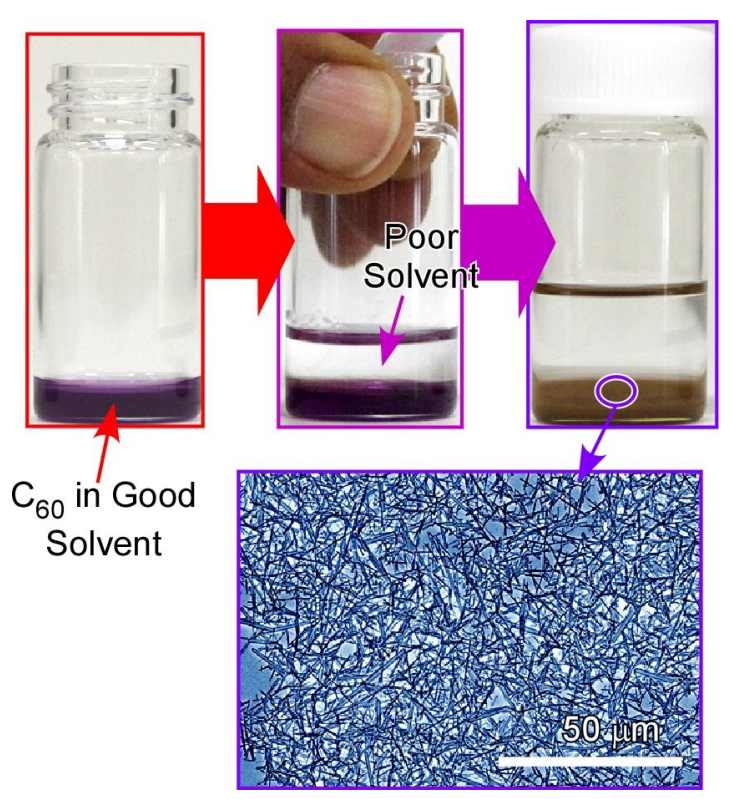

Figure 15: Liquid-liquid interfacial precipitation to fabricate fullerene assemblies (crystals) with various morphologies (in this case, assembly of one-dimensional nanowhiskers). Fullerene molecules, such as $\mathrm{C}_{60}$ and $\mathrm{C}_{70}$, are dissolved in a liquid phase (good solvent) that contacts an immiscible liquid phase in which the molecules are poorly soluble (poor solvent). three-dimensional objects. The final morphology highly depends on type and concentration of the surfactants. When the non-ionic surfactant diglycerol monolaurate was added to butanol $(0.01 \%)$, flower-like three-dimensional objects were precipitated at the interface with benzene. Detailed morphological analyses with electron microscopy techniques revealed that the surfactants did not basically alter primarily the one-dimensional structures of the formed assemblies. Instead, they seemed to promote super-lattice formation constructing three-dimensional flowers form the same one-dimensional rods observed in non-surfactant systems (tubes).

The thermal conversion of one-dimensional fullerene crystalline assemblies at extremely high temperatures resulted in highly graphitic one-dimensional carbon materials as demonstrated by Shrestha and co-workers [242]. One-dimensional $\mathrm{C}_{60}$ nanorods and nanotubes precipitated at liquid-liquid interface were fully carbonized at $2000{ }^{\circ} \mathrm{C}$ in vacuum, resulting in morphology-preserved one-dimensional carbon materials with $\mathrm{sp}^{2}$ hybridised $\pi$-electron-rich robust frameworks (Figure 16). Due to their highly aromatic nature, microbalance sensors with the synthesized one-dimensional carbon materials on a quartz crystal microbalance plate exhibited superior sensing properties for aromatic toxic gasses. In addition, these graphitic carbon 


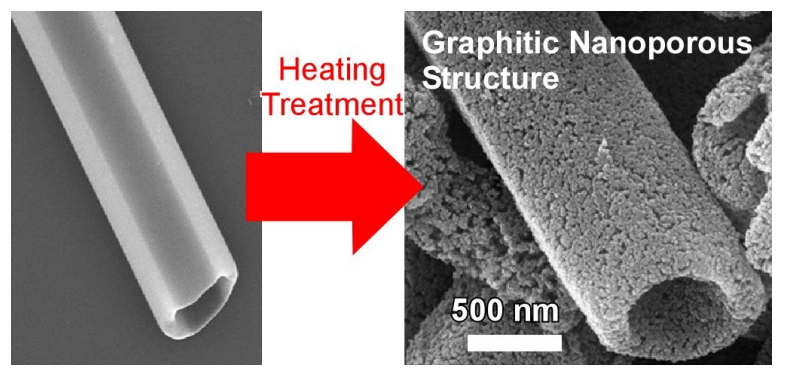

Figure 16: Conversion of one-dimensional $\mathrm{C}_{60}$ nanotubes precipitated at liquid-liquid interface to one-dimensional carbon materials having $\mathrm{sp}^{2}$-carbon-based $\pi$-electron-rich robust mesoporous frameworks through carbonization at $2000^{\circ} \mathrm{C}$ in vacuum.

materials exhibit excellent electrochemical capacitance, suggesting possible usages in electrochemical and electrical applications. A similar nanoarchitectonics strategy was adopted to $\mathrm{C}_{70}$ molecules. The one-dimensional carbon materials prepared through high-temperature carbonization of $\mathrm{C}_{70}$ crystalline assemblies showed high specific capacitances at a high current density and scan rate [243]. These nano-engineered one-dimensional carbon materials might be useful as electrode materials for supercapacitors.

Shrestha, Acharya, and co-workers investigated the optoelectronic properties of one-dimensional $\mathrm{C}_{60}$ nanorods prepared in ultra-rapid ( $5 \mathrm{~s}$ ) processes of liquid-liquid interfacial precipitation at room temperature [244]. Dominant excitonic charge transfer transitions within the nanorods was confirmed by steady-state optical spectroscopy. Photovoltaic cells with onedimensional $\mathrm{C}_{60}$ nanorods as active layer sandwiched by an indium tin oxide anode and an aluminium cathode exhibited enhanced photovoltaic capabilities. It also led to a significant enhancement of photogenerated charge carriers as compared to similar cells prepared with pristine $\mathrm{C}_{60}$ molecules. $\mathrm{C}_{60}$ molecules in a one-dimensional van der Waals solid preserve the electronic structure of $\mathrm{C}_{60}$, but they crystallise in a hexagonal close-packed structure that is different from the cubic crystal structure of pristine $\mathrm{C}_{60}$ molecular crystals. This fact suggests that crystal lattice and molecular packing within low-dimensional fullerene assemblies significantly modify the optoelectronic properties. The rapid synthesis with the possibility to scale-up and the enhanced optoelectronic properties make the above-mentioned nanoarchitectonics strategy for one-dimensional fullerene nanorods a promising approach for applications in photosensitive devices.

$\mathrm{Ji}$, Shrestha, and co-workers investigated the effects of the intercalation of polycyclic aromatic compounds, such as naphthalene, anthracene, and pyrene, on the formation of one-dimensional $\mathrm{C}_{60}$ nanowhiskers in liquid-liquid interfacial precipita- tion processes [245]. The intercalation of polycyclic aromatic compounds generally modifies the growth of fullerene onedimensional crystals depending on intercalation species. While anthracene and pyrene led to an increased porosity of the structures, the structural characteristics of those without intercalator compounds were preserved in the presence of naphthalene. In addition, intercalation of the polycyclic molecules significantly modified the spectral emissions of the fullerene assemblies probably due to effects of molecular packing on the electron transfer within the assembled structures.

Acharya, Shrestha, and co-workers decorated one-dimensional $\mathrm{C}_{60}$ nanorods with zero-dimensional Ag nanoparticles that were used as substrates for surface-enhanced Raman scattering (SERS) to detect model targets such as rhodamine 6G with high sensitivity [246]. This system provides dispersed SERS substrates that can be evaluated by confocal Raman imaging. The nanoarchitectonic materials work as freestanding efficient plasmonic substrates for molecular detection.

Nanoporous bitter-melon-shaped $\mathrm{C}_{60}$ crystals with face-centred cubic lattice were fabricated through liquid-liquid interfacial precipitation from 2-propanol and $\mathrm{C}_{60}$ solution in dodecylbenzene as reported by Shrestha and co-workers (Figure 17) [247]. Quartz crystal microbalance sensors coated with the bittermelon-shaped objects exhibited excellent sensing properties for aromatic vapours with sensitivities in the order of aniline $>$ toluene $>$ benzene $>$ ethanol $>$ hexane $>$ cyclohexane $>$ methanol $>$ water. The obtained nanoporous low-dimensional $\mathrm{C}_{60}$ assemblies provide advantageous features of easy diffusion and promoted $\pi-\pi$ interactions for facile sensing.

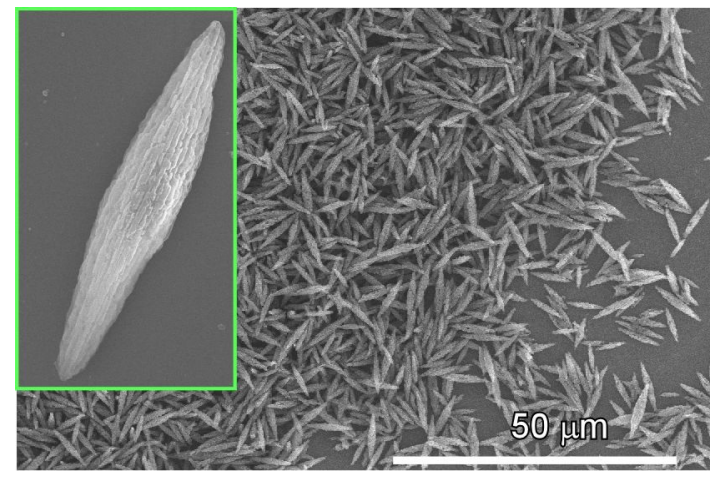

Figure 17: Nanoporous bitter-melon-shaped $\mathrm{C}_{60}$ crystals with facecentered cubic lattice fabricated through liquid-liquid interfacial precipitation methods between isopropyl alcohol and $\mathrm{C}_{60}$ solution in dodecylbenzene.

Saran and Curry reported the use of one-dimensional $\mathrm{C}_{60}$ crystals prepared through liquid-liquid interfacial precipitation between $m$-xylene and isopropyl alcohol for visible-spectrum 
photodetectors [248]. Additional materials or two metal contacts are not necessary in the fabricated photodetectors. These devices made solely from carbon can be used as an alternative to commercial photodetector devices with $\mathrm{CdS}$ and CdSe. Enhanced photoluminescence and photoelectrochemical properties of one-dimensional Lu $\mathrm{Lu}_{2} @ \mathrm{C}_{82}$ nanorods prepared through liquid-liquid interfacial precipitation between carbon disulfide and 2-propanol were demonstrated by Lu and co-workers [249]. Photoluminescence of the one-dimensional $\mathrm{Lu}_{2} @ \mathrm{C}_{82}$ nanorods was remarkably enhanced compared to the pristine $\mathrm{Lu}_{2} @ \mathrm{C}_{82}$ powder. The increased charge carrier transport would be also useful for applications with photoelectric purposes such as photodetectors.

\subsection{Two- and three-dimensional, and hierarchic fullerene assembly materials}

One of the biggest advantages of liquid-liquid interfacial precipitation is the capability of creating nanomaterials with different dimensionalities just by changing the combination of liquids to form the interface. For example, Shrestha and co-workers successfully prepared two-dimensional $\mathrm{C}_{60}$ hexagonal nanosheets with hierarchic pore structures of macropores and mesopores just by changing the solvent combination (Figure 18) [250]. Liquid-liquid interfacial precipitation processes with isopropyl alcohol/benzene and isopropyl alcohol/ carbon tetrachloride provided one-dimensional rods and twodimensional hexagon nanosheets, respectively. While these objects do not possess porous interior structures, the use of good solvents (benzene and carbon tetrachloride) with isopropyl alcohol as poor solvent yielded nanosheets with pores depending on the mixing ratio between benzene and carbon tetrachloride. Incorporation of $30 \%$ carbon tetrachloride changes the morphology from one-dimensional rods to twodimensional hexagonal sheets by preventing the sheets from rolling up to rods. Carbon tetrachloride contents of more than $50 \%$ yielded porous structures of two-dimensional hexagon nanosheets. At $90 \%$ carbon tetrachloride content, the average pore size became ca. $400 \mathrm{~nm}$. These integrated two-dimensional structures would be nanoarchitectonics pieces for the fabrication of sensitive sensors, organic solar cells, and miniaturized organic superconductors.

As a functional development of two-dimensional fullerene objects, Ji, Shrestha, and co-workers reported the synthesis of two-dimensional mesoporous carbon microbelts and demonstrated their usage as electrode material for electrochemical supercapacitors (Figure 19) [251]. Two-dimensional belt-like mesoporous structures can be fabricated from $\mathrm{C}_{60}$ molecules by liquid-liquid interfacial precipitation using a carbon disulfide solution of $\mathrm{C}_{60}$ and isopropyl alcohol. Under optimized conditions, these mesoporous $\mathrm{C}_{60}$ microbelts extended to lengths of

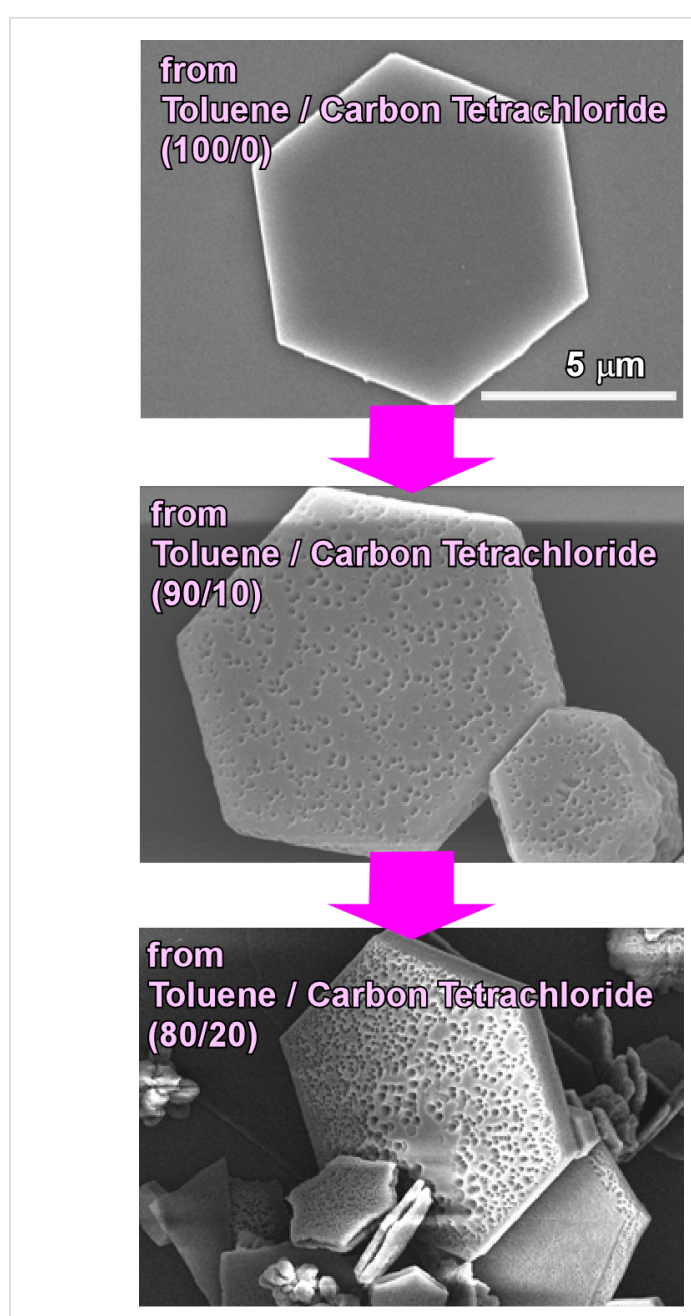

Figure 18: Two-dimensional $\mathrm{C}_{60}$ hexagonal nanosheets with hierarchic pore systems of macropores and mesopores prepared by liquid-liquid interfacial precipitation from isopropyl alcohol and mixtures of benzene and carbon tetrachloride. The porosity can be tuned through the mixing ratio between benzene and carbon tetrachloride. SEM images were reproduced with permission from [68], copyright 2019 The Royal Society of Chemistry.

the order of centimetres. Heat treatment of the obtained $\mathrm{C}_{60}$ microbelts converts them into two-dimensional amorphous carbon microbelts at $900{ }^{\circ} \mathrm{C}$ and their dense graphitic versions at $2000^{\circ} \mathrm{C}$. Especially the former carbon material exhibited excellent electrochemical supercapacitive performance due to the enhanced surface area and the robust mesoporous framework motifs. The hierarchical bimodal pore nature throughout the carbonaceous frameworks results in efficient charge storage and rapid ion transport. Superior cycling stability without any capacity losses even after 10000 charge/discharge cycles was also confirmed.

Furthermore, preparations of three-dimensional and hierarchic structures of fullerene assemblies through liquid-liquid interfacial precipitation have been successfully reported. Shrestha et 


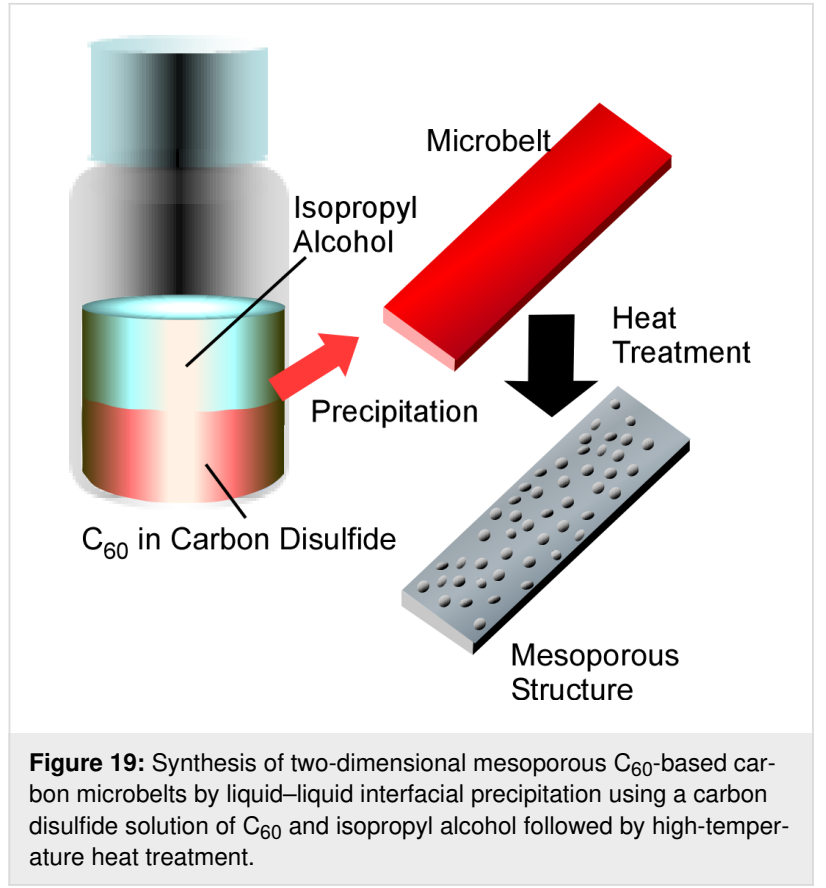

al. reported the synthesis of highly integrated three-dimensional Bucky cubes through liquid-liquid interfacial precipitation and structural transformation by post-solvent treatment (Figure 20) [252]. Three-dimensional cubic structures were precipitated as Olmstead's crystalline $\mathrm{C}_{60}-\mathrm{Ag}(\mathrm{I})$ organometallic hetero-nanostructures $\left[\mathrm{C}_{60}\left\{\mathrm{AgNO}_{3}\right\}_{5}\right]$ at the interface between a saturated benzene solution of $\mathrm{C}_{60}$ and an ethanol solution of silver(I) nitrate. The formed cubic structures underwent structural transformation upon exposing them to aliphatic alcohols of low molecular weight. The transformation of smooth-faced crystals to interpenetrated networks of one-dimensional needle crystals occurred while preserving the cubic shape. Several potential applications based on their electronic and optical properties can be expected for the obtained highly integrated fullerene assemblies.

As reported by Shrestha and co-workers, three-dimensional cubic structures can be fabricated from $\mathrm{C}_{70}$ molecules through an ultrasound-assisted liquid-liquid interfacial precipitation from tert-butyl alcohol and mesitylene [253]. In this modified method, mild sonication was applied for a short period of time after appropriate incubation time. The resulting $\mathrm{C}_{70}$ cubic objects were further transformed into needle-on-cube (onedimensional structure on the surface of three-dimensional object) structures simply by washing with isopropyl alcohol at room temperature (Figure 21). The growth directions and diameters of the nanorod-like $\mathrm{C}_{70}$ one-dimensional structures can be tuned through the washing conditions. Interestingly, the formed nanorod structures possess mesoporous features, which makes the entire structure fully hierarchic. Quartz crystal microbal-

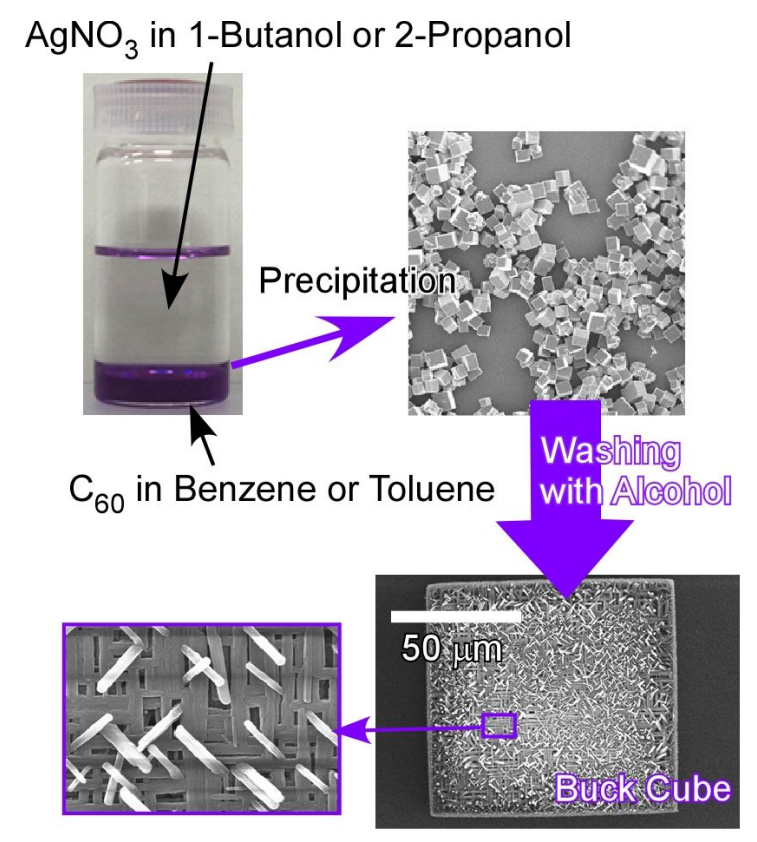

Figure 20: Highly integrated three-dimensional Bucky cubes synthesized by liquid-liquid interfacial precipitation of Olmstead's crystalline $\mathrm{C}_{60}-\mathrm{Ag}(\mathrm{I})$ organometallic heteronanostructure and the subsequent structural transformation upon post-solvent treatment.

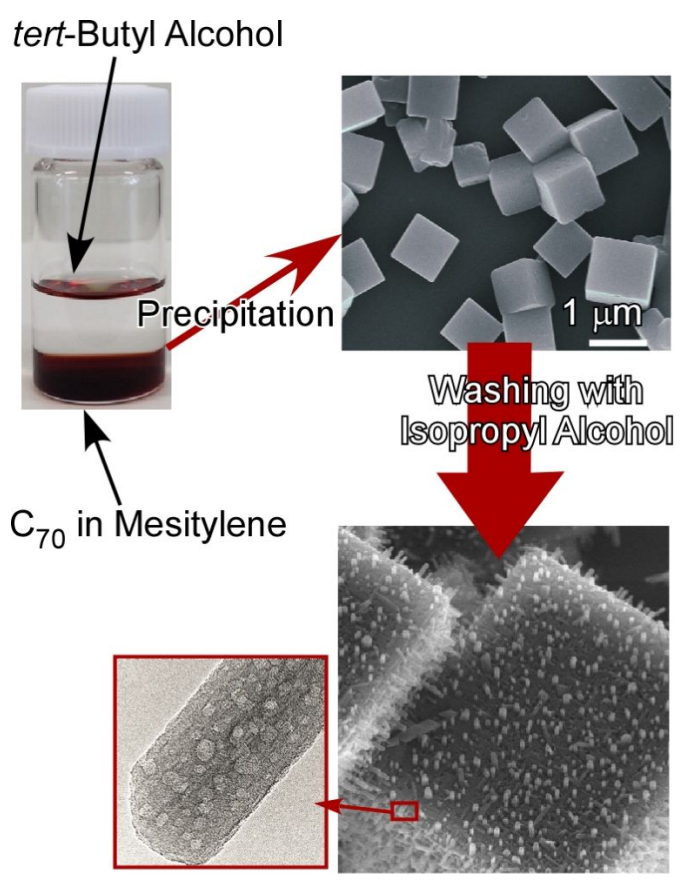

Figure 21: Three-dimensional cubic structures can be fabricated from $\mathrm{C}_{70}$ molecules through an ultrasound-assisted liquid-liquid interfacial precipitation from tert-butyl alcohol and mesitylene. The formed cubes can be further transformed into needle-on-cube (one-dimensional structure on the surface of three-dimensional object) structures simply by washing with isopropyl alcohol at room temperature. Reproduced from [75], copyright 2019 The authors. 
ance sensors modified with these hierarchic $\mathrm{C}_{70}$ assemblies exhibited an excellent sensitivity to aromatic molecules in their vapour phase probably due to facile diffusion through the porous structure, high surface-area contact and advantageous $\pi-\pi$ interaction. The formation of low-dimensional objects from a flat surface efficiently increases the surface area. This strategy of converting low-dimensional structures is beneficial for certain application such as sensing and drug delivery where contact of materials to external media is crucial.

Shrestha and co-workers demonstrated the manipulation of microscopic hole structures on the surface of cubic assemblies of $\mathrm{C}_{70}$ molecules leading to hole-in-cube structures (Figure 22) [254]. Open-hole cubes, in which microscopic holes are formed at center of every face, were fabricated through dynamic liquid-liquid interfacial precipitation from tert-butyl alcohol and mesitylene. In the dynamic procedure, a mesitylene solution of $\mathrm{C}_{70}$ molecules was rapidly added into tert-butyl alcohol and the resulting mixture was further incubated. The closing and re-opening of holes can be controlled through addition of excess $\mathrm{C}_{70}$ molecules and local electron beam irradiation, respectively. Interestingly, the fabricated holes have the capability to discriminate macro-size particles. The holes selectively accommodate graphitic carbon particles instead of resorcinol-formaldehyde resin particles of similar shape and size. Favourable $\pi-\pi$ interactions at the $\mathrm{sp}^{2}$-rich interior surface of the open holes are responsible for this selective capture of microscopic particles.

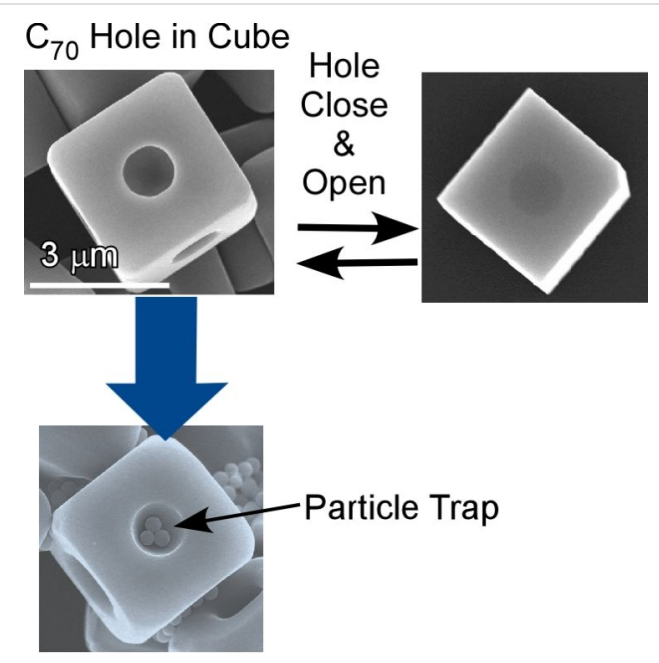

Figure 22: Hole-in-cube structures made from $\mathrm{C}_{70}$ molecules with hole closing and re-opening and particle-trap capability. Reproduced from [75], copyright 2019 The authors.

The preparation of mesoporous crystalline cubes of $\mathrm{C}_{70}$ molecules with unusually enhanced photoluminescence has been recently reported by Shrestha and co-workers [255]. The meso- porous $\mathrm{C}_{70}$ cubes can be prepared by applying a mild heat treatment process to the liquid-liquid interfacial precipitation from tert-butyl alcohol and mesitylene. Initially formed crystalline $\mathrm{C}_{70}$ cubes were transformed into mesoporous $\mathrm{C}_{70}$ cubes via intermediate one-dimensional structures. The resulting mesoporous $\mathrm{C}_{70}$ cubes showed enhanced photoluminescence probably due to their highly crystalline framework structures. In addition, these materials exhibited superior electrochemical supercapacitance over pristine $\mathrm{C}_{70}$ because of their increased electrochemically active surface areas.

Shrestha et al. also reported a modified method of liquid-liquid interfacial precipitation for fullerene nanoarchitectonics using non-ionic surfactants such as diglycerol monolaurate and diglycerol monomyristate [256]. The liquid-liquid precipitation from isopropyl alcohol and ethylbenzene usually provided onedimensional structures. These were, however, transformed into Konpeito candy-like three-dimensional crystalline structures in the presence of the above surfactants in the ethylbenzene phase. Furthermore, the fabricated three-dimensional objects can be graphitized by heat treatment at $2000{ }^{\circ} \mathrm{C}$. The obtained carbon materials show a high potential for applications in energy storage supercapacitor devices.

Liquid-liquid interfacial precipitation methods with the strategies of mixing components and conjugating molecules also create interesting results. Lu, Guldi, and co-workers investigated the co-crystallization of $\mathrm{C}_{70}$ and (metallo)porphyrins through liquid-liquid interfacial precipitation to give two-dimensional nanosheet structures [257]. Single crystal X-ray diffraction studies on the fabricated objects confirmed equimolar fractions of these two components. As indicated by steady-state absorption spectroscopy and fluorescence spectroscopy, a strong charge transfer interaction resulted in the charge separation with one-electron reduced $\mathrm{C}_{70}$ and one-electron oxidized (metallo)porphyrins. $\mathrm{Li}$ and co-workers reported the formation of superstructures of a $\mathrm{C}_{60}$-adamantane conjugate through liquid-liquid interfacial precipitation with chloroform as the good solvent [258]. Diverse morphological structures with various dimensionalities such as spheres, fibers, plates, nanoflowers, cubes and microparticles were obtained.

As an interesting example of two-component fullerene assemblies at liquid-liquid interfaces, Minami, Shrestha, and co-workers demonstrated time-dependent shape shifts of co-assemblies of two fullerene derivatives, pentakis(phenyl)fullerene and pentakis(4-dodecylphenyl)fullerene (Figure 23) [259]. Structural shifts from egg-like structures to tadpole-like structures are regarded as supramolecular differentiation. At the interface of isopropyl alcohol and toluene, egg-like structures were first formed from the mixture of these two components. 


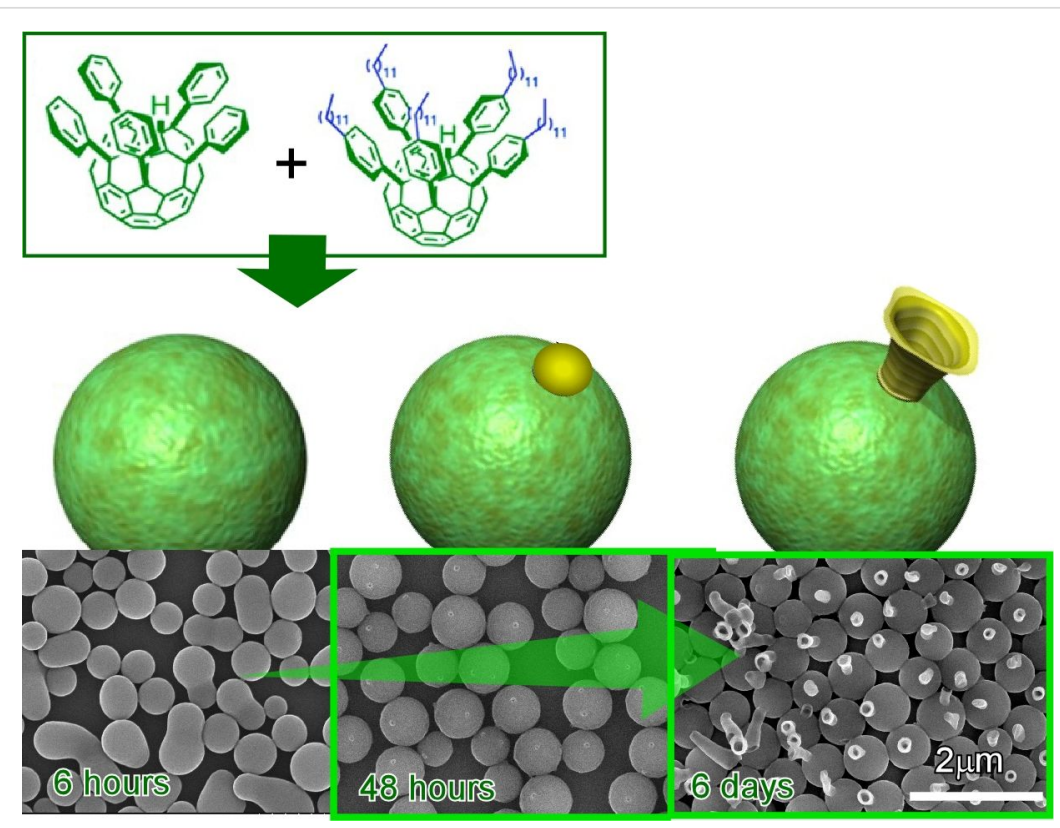

Figure 23: Time-dependent shape shift of co-assemblies of two fullerene derivatives, pentakis(phenyl)fullerene and pentakis(4-dodecylphenyl)fullerene from egg-like structures to tadpole-like structure regarded as supramolecular differentiation. Reproduced from [75], copyright 2019 The Authors.

One or multiple domains of pentakis(4-dodecylphenyl)fullerene appeared on the spherical assemblies of pentakis(phenyl)fullerene using appropriate mixing ratios and appropriate incubation times. From the phase-separated domains, one-dimensional tubular structures of pentakis(4-dodecylphenyl)fullerene preferentially growth as tails upon gentle sonication. The observed supramolecular differentiation can be regarded as the materials-science-based analogue of embryonic development.

\section{Interfacial nanoarchitectonics for biomaterials}

Well-designed biomolecular units should be powerful tools for nanoarchitectonics of low-dimensional materials [260-262]. Asymmetric motifs of biomolecular units can be well designed in many cases and the synthesized asymmetric units are often assembled into low-dimensional structures. As summarized in a recent review article by Matsuura [263], assembled structures of various shapes can be nanoengineered from well-designed biomolecular units such as carbohydrate-conjugated oligodeoxyribonucleotides and three-way junctions of DNA assemblies and oligopeptides. Uses of the assembled low-dimensional materials for drug carriers, ligand-displaying scaffolds, and platform for platforms are anticipated. Sawada and Serizawa explained in their recent review the use of M13 phages for asymmetrical assemblies [264]. Although M13 phages are generally known as useful scaffold for phage-display technology, they utilized the M13 phages as one-dimensional building block for novel liquid crystalline materials. These unique approaches can open a new avenue for phage-based soft materials. He and $\mathrm{Xu}$ reported a novel concept, namely, instructed assembly (iAssembly) [265], which can yield ordered low-dimensional assemblies as the consequence of at least one trigger event. The instructed assembly can be well related to molecular processes to control cell fate.

These examples strikingly indicate that biomaterials have a high potential as building blocks for nanoarchitectonics of functional low-dimensional structures. Restricting these assembly processes two low-dimensional media with certain degrees of motional freedom and diffusional restriction would result in functional low-dimensional materials with attractive biological functions. Liquid interfaces (especially aqueous interfaces) would be appropriate media for this purpose. However, the high surface tension at the air-water interface is disadvantageous for protein assembly because undesirable transformations of secondary structures might be induced by the high surface tension. One method to suppress surface denaturation during twodimensional protein assembly was proposed by Fromherz. The adsorption of proteins from an underneath aqueous subphase to a lipid monolayer at the air-water interface in a multi-compartment trough can prevent undesirable denaturation of proteins [266,267].

Because the method by Fromherz may waste unused proteins in the subphase, it is not always suitable for the two-dimensional assembly of precious biomaterials. In order to overcome this drawback, Okahata and co-workers used lipid-coated proteins 
for a LB process at the air-water interface [268,269]. Watersoluble biomolecules such as proteins were mixed with aqueous vesicles of appropriate lipid molecules, resulting in a waterinsoluble lipid-biomolecule complex. For example, glucose oxidase was complexed with a cationic lipid to provide waterinsoluble materials that were soluble in organic solvents. A benzene solution of the resulting complex was dripped at the air-water interface to give a monolayer film of glucose oxidase and the lipid. The, only the amount of glucose oxidase needed for monolayer formation is required and denaturation of glucose oxidase is avoided by lowering the surface tension through the presence of the lipid. The monolayers were transferred onto a surface of electrodes, leading to glucose detection sensors (Figure 24). Similarly, the presence of additional components such as lipids and polymers is advantageous for other methods of fabricating two-dimensional layered films, such as layer-bylayer assembly [270-273]. Single-enzyme and multi-enzyme reactors were successfully demonstrated [274-276].

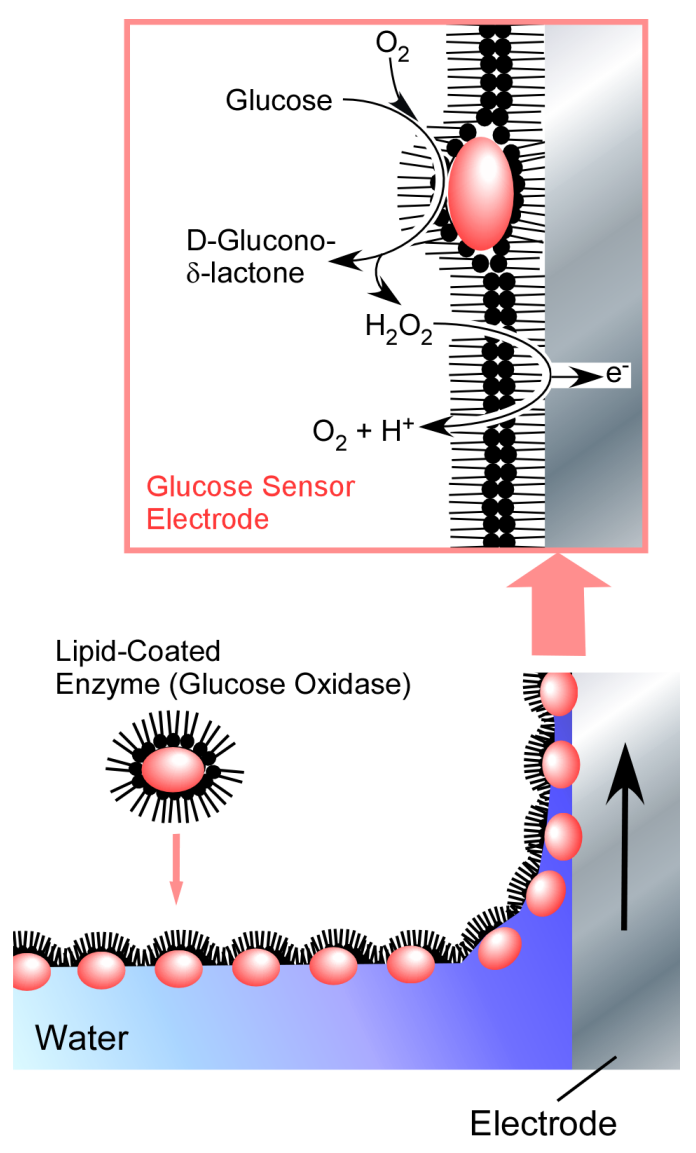

Figure 24: A monolayer of glucose oxidase complexed with a cationic lipid was transferred onto a surface of an electrode for glucose detection sensors.

In addition to the above-mentioned basic efforts in the nanoarchitectonics of bio-components through processes at liquid interfaces, there are more advanced strategies currently under research. For example, the culture, the organization, and the control over the differentiation of living cells have been investigated recently at liquid interfaces. Minami et al. pioneered in the cell differentiation control at a liquid-liquid interface (Figure 25) [277]. Several other research works [278-287] revealed that interfaces between perfluorocarbons and aqueous media are usable for the research of morphological changes, division, and the viability of cells. Minami et al. successfully demonstrated the regulation of myogenic differentiation of C2C12 myoblast cells at water-perfluorocarbon interfaces as fully fluidic microenvironments. While the expression of MyoD remained at the usual level, the expression of myogenic regulatory factors was remarkably attenuated. The observed unusual regulation of myogenic differentiation was attributed to the fluidic nature of the water-perfluorocarbon interfaces. These interfacial cell culture systems might provide good opportunities to study mechanobiological effects in cell science and tissue engineering.

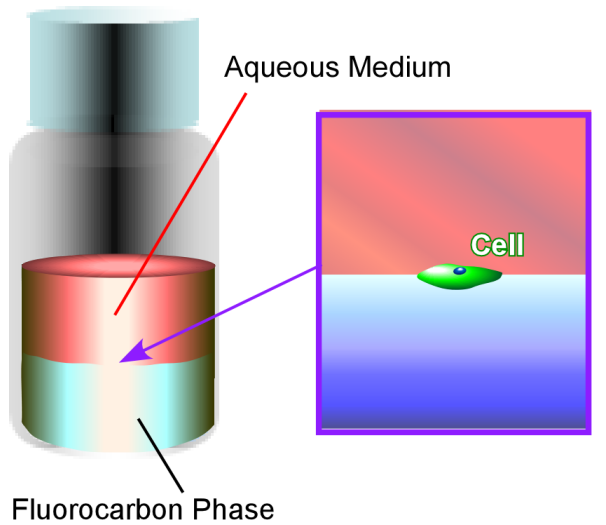

Figure 25: Cultures, organizations, and differentiation controls of living cells a liquid-liquid interface between aqueous media and fluorocarbon phase.

The formation of two-dimensional protein nanosheets and the modulation of stem cell mechanosensing at water-perfluorocarbon interfaces has been recently reported by Jia and co-workers [288]. At the water-perfluorocarbon interfaces, serum proteins were denatured to self-assemble into two-dimensional protein nanosheets. Their packing can be tuned through the selection of the perfluorocarbon compound, e.g., perfluorodecalin or perfluorotributylamine. Human mesenchymal stem cells are mechanically affected by the contact with the twodimensional protein nanosheets. Spreading, adhesion growth, and yes-associated protein nuclear translocation of the cells were triggered by a greater stiffness of the two-dimensional protein nanosheets. The observed behaviour can be explained by a molecular clutch model (Figure 26). The underlying two- 


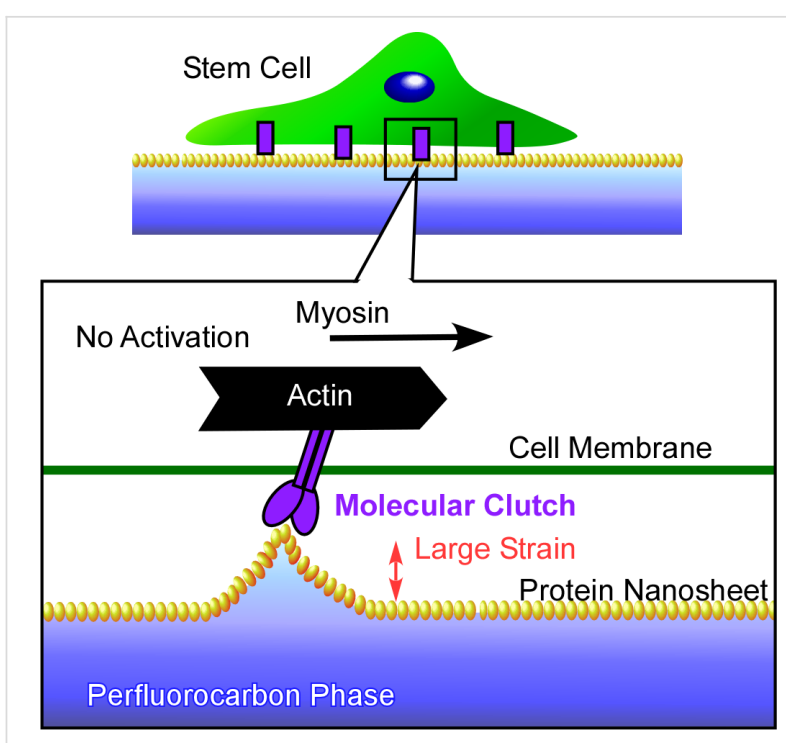

Figure 26: Human mesenchymal stem cells at the interface between aqueous medium and fluorocarbon phase with self-grown two-dimensional protein nanosheets at which the mechanical behaviour of cells can be explained by a molecular clutch model.

dimensional protein nanosheets are extremely flexible and exhibit a large strain upon traction by the cells, which is probably greater than the effect from solid surfaces. The obtained results are useful for the understanding of interactions between cells and materials at liquid interfacial media, as well as in the development of stem cell culture media, and regenerative therapies.

Yang and co-workers also demonstrated the fabrication of twodimensional amyloid-like ultrathin two-dimensional protein membranes at the air-water interface [289]. The membranes are formed through fast aggregation of amyloid-like lysozyme molecules with controllable thickness from 30 to $250 \mathrm{~nm}$ accompanied by the formation of pores with diameters of 1.8 to $3.2 \mathrm{~nm}$. While the two-dimensional membranes allow for a rather fast permeation of small substances, molecules and particles larger than $3 \mathrm{~nm}$ are retained at the membrane. Therefore, these twodimensional materials exhibited an excellent hemodialysis capability to remove uremic toxins of medium molecular weight. The fabricated two-dimensional protein materials might be applied in pressure-driven filtration, size-directed forward osmosis, and large-scale dialysis systems.

Instead of spontaneously formed low-dimensional protein materials, low-dimensional fullerene materials artificially prepared at liquid interfaces have been used for the regulation of cell alignment and differentiation. Krishnan et al. applied a novel vortex $\mathrm{LB}$ method to align one-dimensional $\mathrm{C}_{60}$ nanowhiskers with controlled alignment and curvature (Figure 27) [290]. As described above, the vortex LB method utilizes the air-water interface with a vortex rotation of one subphase, which can

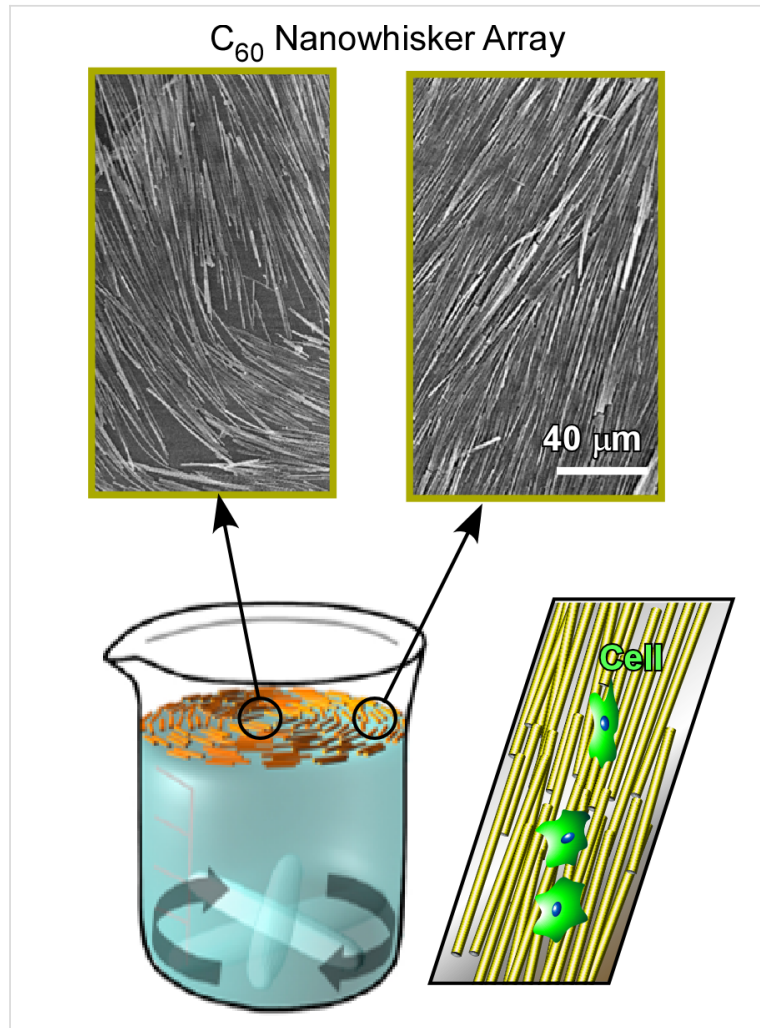

Figure 27: One-dimensional $\mathrm{C}_{60}$ nanowhiskers with controlled alignment and curvature fabricated by a vortex LB method for the culture of bone-forming human osteoblast MG63 cells.

align one-dimensional $\mathrm{C}_{60}$ nanowhiskers to the flow direction. The aligned nanowhiskers can be also transferred onto a solid substrate but their geometry can be regulated through the selection of the transfer position from the centre of vortex motion. While a transfer far from the centre resulted in almost parallel alignment, curved alignment can be obtained through transfer from near the vortex centre. The aligned $\mathrm{C}_{60}$ nanowhisker arrays were used as a scaffold for the culture of bone-forming human osteoblast MG63 cells. Cell growth occurred mostly along the axis of the aligned one-dimensional $\mathrm{C}_{60}$ nanowhiskers. In addition, the low toxicity of the $\mathrm{C}_{60}$ nanowhiskers was confirmed by cell proliferation test.

Minami et al. investigated the regulation of macroscopic cell orientation and differentiation of mouse skeletal myoblast C2C12 cells [291]. Highly aligned $\mathrm{C}_{60}$ nanowhisker arrays on a solid surface were fabricated via conventional LB transfer from the air-water interface. The culture of $\mathrm{C} 2 \mathrm{C} 12$ cells on the aligned $\mathrm{C}_{60}$ nanowhiskers led to a significant enhancement of myotube formation with highly regulated directional growth. Hsu and co-workers proposed the fabrication of highly oriented and well-aligned arrays of one-dimensional $\mathrm{C}_{60}$ nanowhiskers through the modification of motion in a dynamic LB process [292]. Instead of vortex rotational motion, they used a recip- 
rocal (shaking) motion in one direction for a monolayer of $\mathrm{C}_{60}$ nanowhiskers at the air-water interface, resulting in arrays of $\mathrm{C}_{60}$ nanowhiskers with a higher degree of alignment (Figure 28). The differentiation of neural stem cells on highly aligned $\mathrm{C}_{60}$ nanowhiskers was investigated to show their enhanced viability and their differentiation into mature neurons. Because of the biocompatibility of the used one-dimensional $\mathrm{C}_{60}$ nanowhiskers and the high potential for large-area fabrication, the presented $\mathrm{C}_{60}$ scaffolds might be a promising platform for patterned cell scaffolds for tissue engineering.

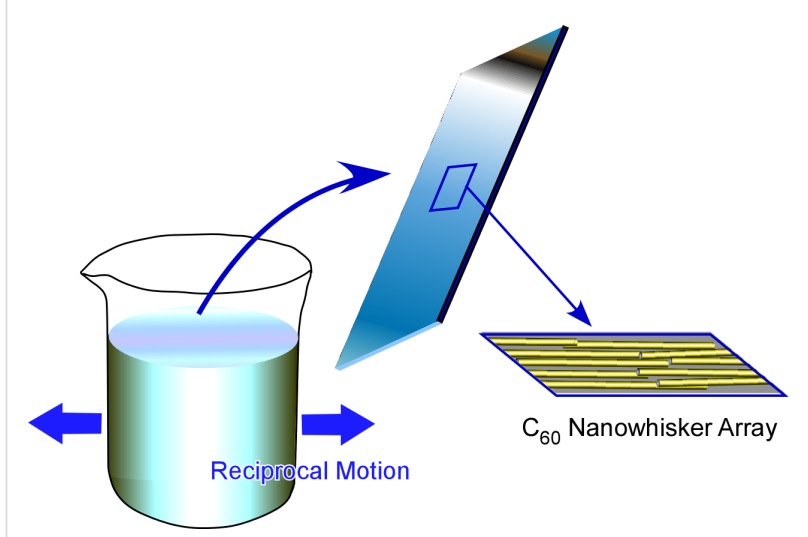

Figure 28: Highly aligned arrays of $\mathrm{C}_{60}$ nanowhiskers obtained by using a LB method with reciprocal motion in one direction for differentiation control of neural stem cells.

Highly expressible bacteriorhodopsin is known as a light-sensitive opsin with the potential capability of triggering neuronal activities through optogenetic modulation [293]. Optogenetic modulation and reprogramming of human fibroblasts transfected by highly expressible bacteriorhodopsin was investigated by $\mathrm{Hsu}$ and co-workers using tow-dimensional $\mathrm{C}_{60}$ nanosheets [294]. The transfected fibroblasts cultured on $\mathrm{C}_{60}$ nanosheets with controlled light illumination induced reprogramming and differentiation into neural cells. This approach may indicate the possibility to control cell differentiation by selective location (on two-dimensional $\mathrm{C}_{60}$ nanosheets) and timing (illumination time).

\section{Conclusion and Perspectives}

For designing advanced functions within a small space, the selective and anisotropic organization of materials, energy, electrons, and information is indispensable. One of the promising methods to obtain such a unique aggregated state would be using low-dimensional anisotropic systems and materials. Lowdimensional materials including nanoparticle, nanorods, and nanosheets have been paid much attention in science and technology in this context recently. In addition to conventional lowdimensional materials such as fullerene, carbon nanotubes, graphene and various two-dimensional materials, constructing novel low-dimensional materials from a wide range of nanomaterials precursors is an attractive research field. A novel concept called nanoarchitectonics in which functional materials are engineered from nanoscale components, might be the best methodology for this objective. Especially, the use of dynamic interfacial media providing a unique restriction the molecular motion is advantageous for the facile synthesis of anisotropic low-dimensional materials.

Based on these general considerations, this review described bottom-up syntheses of low-dimensional systems and materials using materials nanoarchitectonics at two-dimensional liquid interfaces. The contents of the review article range from the description of basic characteristics of interfacial media with specific features of molecular interactions to various materials systems including molecular patterns, two-dimensional $\mathrm{MOF} / \mathrm{COF}$, low-dimensional nanocarbons, and biomaterial assemblies including living cells at liquid interfaces. Methodologies to realize materials nanoarchitectonics at two-dimensional liquid interfaces make use of various aspects and functions of low-dimensional systems and materials including the control of fundamental molecular interactions that regulate complicated cell functions. A generality of nanoarchitectonics concepts at liquid interfaces for low-dimensional systems and materials can be found in the examples introduced in this review.

For future developments of the nanoarchitectonics strategy, two essential features need to be considered in more detail. The first is the control of functional component units within low-dimensional materials, especially in two-dimensional planes. Very advanced functions seen in biological systems such as energy conversion and signal transduction highly rely on sophisticated arrangements and organizations of functional elements within two-dimensional cell membranes. These sophisticated biological systems need to be studied more extensively as an ideal example of low-dimensional functional materials. The regulation of the organization of functional components within low-dimensional structures would be a key methodology to develop lowdimensional systems to the next stage. Another key requirement of nanoarchitectonics would be the development of largescale production. Most of research efforts on nanoarchitectonics-based low-dimensional materials are still at the laboratory scale, which is not attractive for further industrial developments. The use of low-cost precursors and application examples that can be realized with simple technical procedures would be important. Upon technical development according to these required features, low-dimensional systems and materials might give more opportunities to design advanced functions for industrial applications. 


\section{Acknowledgements}

This study was partially supported by JSPS KAKENHI Grant Number JP16H06518 (Coordination Asymmetry) and CREST JST Grant Number JPMJCR1665.

\section{ORCID ${ }^{\circledR}$ iDs}

Katsuhiko Ariga - https://orcid.org/0000-0002-2445-2955

Taizo Mori - https://orcid.org/0000-0002-6974-5137

Lok Kumar Shrestha - https://orcid.org/0000-0003-2680-6291

\section{References}

1. Silvestre, B. S.; Tîrcă, D. M. J. Cleaner Prod. 2019, 208, 325-332. doi:10.1016/j.jclepro.2018.09.244

2. Povie, G.; Segawa, Y.; Nishihara, T.; Miyauchi, Y.; Itami, K. Science 2017, 356, 172-175. doi:10.1126/science.aam8158

3. Wang, Y.; Michinobu, T. Bull. Chem. Soc. Jpn. 2017, 90, 1388-1400. doi:10.1246/bcsj.20170294

4. Takimiya, K.; Nakano, M. Bull. Chem. Soc. Jpn. 2018, 91, 121-140. doi:10.1246/bcsj.20170298

5. Sun, Z.; Matsuno, T.; Isobe, H. Bull. Chem. Soc. Jpn. 2018, 91, 907-921. doi:10.1246/bcsj.20180051

6. Sun, Z.; Ikemoto, K.; Fukunaga, T. M.; Koretsune, T.; Arita, R.; Sato, S.; Isobe, H. Science 2019, 363, 151-155. doi:10.1126/science.aau5441

7. Soloviev, I. I.; Klenov, N. V.; Bakurskiy, S. V.; Kupriyanov, M. Y.; Gudkov, A. L.; Sidorenko, A. S. Beilstein J. Nanotechnol. 2017, 8, 2689-2710. doi:10.3762/bjnano.8.269

8. Taniguchi, M. Bull. Chem. Soc. Jpn. 2017, 90, 1189-1210. doi:10.1246/bcsj.20170224

9. Su, V.-C.; Chu, C. H.; Sun, G.; Tsai, D. P. Opt. Express 2018, 26 , 13148-13182. doi:10.1364/oe.26.013148

10. Huang, X.; Wang, J.; Li, T.; Wang, J.; Xu, M.; Yu, W.; El Abed, A.; Zhang, X. Beilstein J. Nanotechnol. 2018, 9, 30-41. doi:10.3762/bjnano.9.5

11. Nishizawa, M. Bull. Chem. Soc. Jpn. 2018, 91, 1141-1149. doi:10.1246/bcsj.20180064

12. Li, J.-F.; Zhang, Y.-J.; Ding, S.-Y.; Panneerselvam, R.; Tian, Z.-Q. Chem. Rev. 2017, 117, 5002-5069. doi:10.1021/acs.chemrev.6b00596

13. Mizutani, Y. Bull. Chem. Soc. Jpn. 2017, 90, 1344-1371. doi:10.1246/bcsj.20170218

14. Zrimsek, A. B.; Chiang, N.; Mattei, M.; Zaleski, S.; McAnally, M. O.; Chapman, C. T.; Henry, A.-I.; Schatz, G. C.; Van Duyne, R. P. Chem. Rev. 2017, 117, 7583-7613. doi:10.1021/acs.chemrev.6b00552

15. Ruiz-Hitzky, E.; Gómez-Avilés, A.; Darder, M.; Aranda, P. Bull. Chem. Soc. Jpn. 2018, 91, 608-616. doi:10.1246/bcsj.20170425

16. Einaga, Y. Bull. Chem. Soc. Jpn. 2018, 91, 1752-1762. doi:10.1246/bcsj.20180268

17. Hu, M.; Reboul, J.; Furukawa, S.; Torad, N. L.; Ji, Q.; Srinivasu, P.; Ariga, K.; Kitagawa, S.; Yamauchi, Y. J. Am. Chem. Soc. 2012, 134, 2864-2867. doi:10.1021/ja208940u

18. Chaikittisilp, W.; Torad, N. L.; Li, C.; Imura, M.; Suzuki, N.; Ishihara, S.; Ariga, K.; Yamauchi, Y. Chem. - Eur. J. 2014, 20 , 4217-4221. doi:10.1002/chem.201304404

19. Malgras, V.; Ji, Q.; Kamachi, Y.; Mori, T.; Shieh, F.-K.; Wu, K. C.-W.; Ariga, K.; Yamauchi, Y. Bull. Chem. Soc. Jpn. 2015, 88, 1171-1200. doi:10.1246/bcsj.20150143
20. Wei, Q.; Xiong, F.; Tan, S.; Huang, L.; Lan, E. H.; Dunn, B.; Mai, L. Adv. Mater. (Weinheim, Ger.) 2017, 29, 1602300. doi:10.1002/adma.201602300

21. Gon, M.; Tanaka, K.; Chujo, Y. Bull. Chem. Soc. Jpn. 2017, 90, 463-474. doi:10.1246/bcsj.20170005

22. Jana, A.; Scheer, E.; Polarz, S. Beilstein J. Nanotechnol. 2017, 8, 688-714. doi:10.3762/bjnano.8.74

23. Yao, Q.; Yuan, X.; Chen, T.; Leong, D. T.; Xie, J. Adv. Mater. (Weinheim, Ger.) 2018, 30, 1802751. doi:10.1002/adma.201802751

24. Kobayashi, Y. Bull. Chem. Soc. Jpn. 2018, 91, 467-485. doi:10.1246/bcsj.20170374

25. Chaikittisilp, W.; Hu, M.; Wang, H.; Huang, H.-S.; Fujita, T.; Wu, K. C.-W.; Chen, L.-C.; Yamauchi, Y.; Ariga, K. Chem. Commun. 2012, 48, 7259-7261. doi:10.1039/c2cc33433j

26. Torad, N. L.; Hu, M.; Ishihara, S.; Sukegawa, H.; Belik, A. A.; Imura, M.; Ariga, K.; Sakka, Y.; Yamauchi, Y. Small 2014, 10, 2096-2107. doi:10.1002/smll.201302910

27. Guo, D.; Shibuya, R.; Akiba, C.; Saji, S.; Kondo, T.; Nakamura, J. Science 2016, 351, 361-365. doi:10.1126/science.aad0832

28. Kumar, S.; Kumar, A.; Bahuguna, A.; Sharma, V.; Krishnan, V. Beilstein J. Nanotechnol. 2017, 8, 1571-1600. doi:10.3762/bjnano.8.159

29. Stauss, S.; Honma, I. Bull. Chem. Soc. Jpn. 2018, 91, 492-505. doi:10.1246/bcsj.20170325

30. Miyasaka, T. Bull. Chem. Soc. Jpn. 2018, 91, 1058-1068. doi:10.1246/bcsj.20180071

31. Watanabe, M.; Dokko, K.; Ueno, K.; Thomas, M. L. Bull. Chem. Soc. Jpn. 2018, 91, 1660-1682. doi:10.1246/bcsj.20180216

32. Egorova, K. S.; Gordeev, E. G.; Ananikov, V. P. Chem. Rev. 2017, 117, 7132-7189. doi:10.1021/acs.chemrev.6b00562

33. Saptiama, I.; Kaneti, Y. V.; Suzuki, Y.; Suzuki, Y.; Tsuchiya, K.; Sakae, T.; Takai, K.; Fukumitsu, N.; Alothman, Z. A.; Hossain, M. S. A.; Ariga, K.; Yamauchi, Y. Bull. Chem. Soc. Jpn. 2017, 90, 1174-1179. doi:10.1246/bcsj.20170184

34. Chou, K.-C. Curr. Top. Med. Chem. 2017, 17, 2337-2358. doi:10.2174/1568026617666170414145508

35. Asanuma, H.; Murayama, K.; Kamiya, Y.; Kashida, H. Bull. Chem. Soc. Jpn. 2018, 91, 1739-1748. doi:10.1246/bcsj.20180278

36. Zheng, K.; Setyawati, M. I.; Leong, D. T.; Xie, J. Coord. Chem. Rev. 2018, 357, 1-17. doi:10.1016/j.ccr.2017.11.019

37. Saptiama, I.; Kaneti, Y. V.; Oveisi, H.; Suzuki, Y.; Tsuchiya, K.; Takai, K.; Sakae, T.; Pradhan, S.; Hossain, M. S. A.; Fukumitsu, N.; Ariga, K.; Yamauchi, Y. Bull. Chem. Soc. Jpn. 2018, 91, 195-200. doi:10.1246/bcsj.20170295

38. Kiguchi, M.; Fujii, S. Bull. Chem. Soc. Jpn. 2017, 90, 1-11. doi:10.1246/bcsj.20160229

39. Yamamura, A.; Watanabe, S.; Uno, M.; Mitani, M.; Mitsui, C.; Tsurumi, J.; Isahaya, N.; Kanaoka, Y.; Okamoto, T.; Takeya, J. Sci. Adv. 2018, 4, eaao5758. doi:10.1126/sciadv.aao5758

40. Acharya, S.; Hill, J. P.; Ariga, K. Adv. Mater. (Weinheim, Ger.) 2009, 21, 2959-2981. doi:10.1002/adma.200802648

41. Wang, R.; Lu, K.-Q.; Tang, Z.-R.; Xu, Y.-J. J. Mater. Chem. A 2017, 5, 3717-3734. doi:10.1039/c6ta08660h

42. Lodahl, P.; Mahmoodian, S.; Stobbe, S.; Rauschenbeutel, A.; Schneeweiss, P.; Volz, J.; Pichler, H.; Zoller, P. Nature 2017, 541 , 473-480. doi:10.1038/nature21037 
43. Nakano, K.; Honda, T.; Yamasaki, K.; Tanaka, Y.; Taniguchi, K.; Ishimatsu, R.; Imato, T. Bull. Chem. Soc. Jpn. 2018, 91, 1128-1130. doi:10.1246/bcsj.20180095

44. Ding, X.; Peng, F.; Zhou, J.; Gong, W.; Slaven, G.; Loh, K. P.; Lim, C. T.; Leong, D. T. Nat. Commun. 2019, 10, 41. doi:10.1038/s41467-018-07835-1

45. Datta, K. K. R.; Reddy, B. V. S.; Ariga, K.; Vinu, A. Angew. Chem., Int. Ed. 2010, 49, 5961-5965. doi:10.1002/anie.201001699

46. Shirai, H.; Nguyen, M. T.; Čempel, D.; Tsukamoto, H.; Tokunaga, T.; Liao, Y.-C.; Yonezawa, T. Bull. Chem. Soc. Jpn. 2017, 90, 279-285. doi:10.1246/bcsj.20160333

47. Huang, R.; Chen, H.; Xia, Z. Bull. Chem. Soc. Jpn. 2017, 90, 754-759. doi:10.1246/bcsj.20170016

48. Choukourov, A.; Pleskunov, P.; Nikitin, D.; Titov, V.; Shelemin, A.; Vaidulych, M.; Kuzminova, A.; Solař, P.; Hanuš, J.; Kousal, J.; Kylián, O.; Slavínská, D.; Biederman, H. Beilstein J. Nanotechnol. 2017, 8, 2002-2014. doi:10.3762/bjnano.8.200

49. Bhattacharyya, K.; Mukherjee, S. Bull. Chem. Soc. Jpn. 2018, 91 , 447-454. doi:10.1246/bcsj.20170377

50. Kani, K.; Zakaria, M. B.; Lin, J.; Alshehri, A. A.; Kim, J.; Bando, Y.; You, J.; Hossain, M. S. A.; Bo, J.; Yamauchi, Y. Bull. Chem. Soc. Jpn. 2018, 91, 1333-1336. doi:10.1246/bcsj.20180129

51. Yonezawa, T.; Čempel, D.; Nguyen, M. T. Bull. Chem. Soc. Jpn. 2018, 91, 1781-1798. doi:10.1246/bcsj.20180285

52. Zhang, R.; Zhang, Y.; Wei, F. Chem. Soc. Rev. 2017, 46, 3661-3715. doi:10.1039/c7cs00104e

53. Kharlamova, M. V. Beilstein J. Nanotechnol. 2017, 8, 826-856. doi:10.3762/bjnano.8.85

54. Clancy, A. J.; Anthony, D. B.; Fisher, S. J.; Leese, H. S.; Roberts, C. S.; Shaffer, M. S. P. Nanoscale 2017, 9, 8764-8773. doi:10.1039/c7nr00734e

55. Chen, R.; Kang, J.; Kang, M.; Lee, H.; Lee, H. Bull. Chem. Soc. Jpn. 2018, 91, 979-990. doi:10.1246/bcsj.20180042

56. Ji, Q.; Honma, I.; Paek, S.-M.; Akada, M.; Hill, J. P.; Vinu, A.; Ariga, K. Angew. Chem., Int. Ed. 2010, 49, 9737-9739. doi:10.1002/anie.201004929

57. Anasori, B.; Lukatskaya, M. R.; Gogotsi, Y. Nat. Rev. Mater. 2017, 2, 16098. doi:10.1038/natrevmats.2016.98

58. Khan, A. H.; Ghosh, S.; Pradhan, B.; Dalui, A.; Shrestha, L. K.; Acharya, S.; Ariga, K. Bull. Chem. Soc. Jpn. 2017, 90, 627-648. doi:10.1246/bcsj.20170043

59. Manzeli, S.; Ovchinnikov, D.; Pasquier, D.; Yazyev, O. V.; Kis, A. Nat. Rev. Mater. 2017, 2, 17033. doi:10.1038/natrevmats.2017.33

60. Ariga, K.; Watanabe, S.; Mori, T.; Takeya, J. NPG Asia Mater. 2018, 10, 90-106. doi:10.1038/s41427-018-0022-9

61. Maeda, K.; Mallouk, T. E. Bull. Chem. Soc. Jpn. 2019, 92, 38-54. doi:10.1246/bcsj.20180258

62. Ulaganathan, R. K.; Chang, Y.-H.; Wang, D.-Y.; Li, S.-S. Bull. Chem. Soc. Jpn. 2018, 91, 761-771. doi:10.1246/bcsj.20180016

63. Sakamoto, R. Bull. Chem. Soc. Jpn. 2017, 90, 272-278. doi:10.1246/bcsj.20160304

64. Liu, J.; Chen, Q.-W.; Wu, K. Chin. Chem. Lett. 2017, 28, 1631-1639. doi:10.1016/j.cclet.2017.04.022

65. Ariga, K.; Mori, T.; Shrestha, L. K. Chem. Rec. 2018, 18, 676-695. doi:10.1002/tcr.201700070

66. Cao, L.; Wang, T.; Wang, C. Chin. J. Chem. 2018, 36, 754-764. doi:10.1002/cjoc.201800144

67. Wang, Y.; Mayorga-Martinez, C. C.; Pumera, M. Bull. Chem. Soc. Jpn. 2017, 90, 847-853. doi:10.1246/bcsj.20170076
68. Ariga, K.; Jia, X.; Shrestha, L. K. Mol. Syst. Des. Eng. 2019, 4, 49-64. doi:10.1039/c8me00094h

69. Seki, T. Bull. Chem. Soc. Jpn. 2018, 91, 1026-1057. doi:10.1246/bcsj.20180076

70. Vinu, A.; Miyahara, M.; Ariga, K. J. Nanosci. Nanotechnol. 2006, 6, 1510-1532. doi:10.1166/jnn.2006.253

71. Katagiri, K.; Hashizume, M.; Ariga, K.; Terashima, T.; Kikuchi, J.-i. Chem. - Eur. J. 2007, 13, 5272-5281. doi:10.1002/chem.200700175

72. Ariga, K.; Hill, J. P.; Lee, M. V.; Vinu, A.; Charvet, R.; Acharya, S. Sci. Technol. Adv. Mater. 2008, 9, 014109. doi:10.1088/1468-6996/9/1/014109

73. Ariga, K.; Hill, J. P.; Ji, Q. Macromol. Biosci. 2008, 8, 981-990. doi:10.1002/mabi.200800102

74. Haketa, Y.; Maeda, H. Bull. Chem. Soc. Jpn. 2018, 91, 420-436. doi:10.1246/bcsj.20170434

75. Ariga, K.; Nishikawa, M.; Mori, T.; Takeya, J.; Shrestha, L. K.; Hill, J. P. Sci. Technol. Adv. Mater. 2019, 20, 51-95. doi:10.1080/14686996.2018.1553108

76. Hiraoka, S. Bull. Chem. Soc. Jpn. 2018, 91, 957-978. doi:10.1246/bcsj.20180008

77. Dhiman, S.; George, S. J. Bull. Chem. Soc. Jpn. 2018, 91, 687-699. doi:10.1246/bcsj.20170433

78. Shimizu, T. Bull. Chem. Soc. Jpn. 2018, 91, 623-668. doi:10.1246/bcsj.20170424

79. Komiyama, M.; Mori, T.; Ariga, K. Bull. Chem. Soc. Jpn. 2018, 91, 1075-1111. doi:10.1246/bcsj.20180084

80. Akamatsu, M.; Komatsu, H.; Matsuda, A.; Mori, T.; Nakanishi, W.; Sakai, H.; Hill, J. P.; Ariga, K. Bull. Chem. Soc. Jpn. 2017, 90, 678-683. doi:10.1246/bcsj.20170046

81. Suda, M. Bull. Chem. Soc. Jpn. 2018, 91, 19-28. doi:10.1246/bcsj.20170283

82. Abdullayev, E.; Sakakibara, K.; Okamoto, K.; Wei, W.; Ariga, K.; Lvov, Y. ACS Appl. Mater. Interfaces 2011, 3, 4040-4046. doi:10.1021/am200896d

83. Vinokurov, V. A.; Stavitskaya, A. V.; Chudakov, Y. A.; Ivanov, E. V.; Shrestha, L. K.; Ariga, K.; Darrat, Y. A.; Lvov, Y. M. Sci. Technol. Adv. Mater. 2017, 18, 147-151. doi:10.1080/14686996.2016.1278352

84. Glotov, A.; Stavitskaya, A.; Chudakov, Y.; Ivanov, E.; Huang, W.; Vinokurov, V.; Zolotukhina, A.; Maximov, A.; Karakhanov, E.; Lvov, Y. Bull. Chem. Soc. Jpn. 2019, 92, 61-69. doi:10.1246/bcsj.20180207

85. Zhong, S.; Xu, Q. Bull. Chem. Soc. Jpn. 2018, 91, 1606-1617. doi:10.1246/bcsj.20180227

86. Sengottaiyan, C.; Jayavel, R.; Bairi, P.; Shrestha, R. G.; Ariga, K.; Shrestha, L. K. Bull. Chem. Soc. Jpn. 2017, 90, 955-962. doi:10.1246/bcsj.20170092

87. Li, B. L.; Setyawati, M. I.; Chen, L.; Xie, J.; Ariga, K.; Lim, C.-T.; Garaj, S.; Leong, D. T. ACS Appl. Mater. Interfaces 2017, 9 , 15286-15296. doi:10.1021/acsami.7b02529

88. Ariga, K.; Ji, Q.; Hill, J. P.; Bando, Y.; Aono, M. NPG Asia Mater. 2012, 4, e17. doi:10.1038/am.2012.30

89. Ariga, K.; Ji, Q.; Nakanishi, W.; Hill, J. P.; Aono, M. Mater. Horiz. 2015, 2, 406-413. doi:10.1039/c5mh00012b

90. Ariga, K.; Yamauchi, Y.; Aono, M. APL Mater. 2015, 3, 061001. doi:10.1063/1.4922549

91. Ariga, K.; Aono, M. Jpn. J. Appl. Phys. 2016, 55, 1102 A6. doi:10.7567/jjap.55.1102a6

92. Ariga, K.; Li, M.; Richards, G.; Hill, J. J. Nanosci. Nanotechnol. 2011, 11, 1-13. doi:10.1166/jnn.2011.3839 
93. Ariga, K.; Li, J.; Fei, J.; Ji, Q.; Hill, J. P. Adv. Mater. (Weinheim, Ger.) 2016, 28, 1251-1286. doi:10.1002/adma.201502545

94. Shirai, Y.; Minami, K.; Nakanishi, W.; Yonamine, Y.; Joachim, C.; Ariga, K. Jpn. J. Appl. Phys. 2016, 55, 1102 A2. doi:10.7567/jjap.55.1102a2

95. Aono, M.; Ariga, K. Adv. Mater. (Weinheim, Ger.) 2016, 28, 989-992. doi:10.1002/adma.201502868

96. Ariga, K. Mater. Chem. Front. 2017, 1, 208-211. doi:10.1039/c6qm00240d

97. Ariga, K.; Vinu, A.; Yamauchi, Y.; Ji, Q.; Hill, J. P. Bull. Chem. Soc. Jpn. 2012, 85, 1-32. doi:10.1246/bcsj.20110162

98. Govindaraju, T.; Avinash, M. B. Nanoscale 2012, 4, 6102-6117. doi:10.1039/c2nr31167d

99. Ramanathan, M.; Shrestha, L. K.; Mori, T.; Ji, Q.; Hill, J. P.; Ariga, K. Phys. Chem. Chem. Phys. 2013, 15, 10580-10611. doi:10.1039/c3cp50620g

100.Zerkoune, L.; Angelova, A.; Lesieur, S. Nanomaterials 2014, 4, 741-765. doi:10.3390/nano4030741

101.Ariga, K.; Ji, Q.; Nakanishi, W.; Hill, J. P. J. Inorg. Organomet. Polym. Mater. 2015, 25, 466-479. doi:10.1007/s10904-015-0179-4

102.Shrestha, L. K.; Strzelczyk, K. M.; Shrestha, R. G.; Ichikawa, K.; Aramaki, K.; Hill, J. P.; Ariga, K. Nanotechnology 2015, 26, 204002. doi:10.1088/0957-4484/26/20/204002

103. Hecht, S. Angew. Chem., Int. Ed. 2003, 42, 24-26. doi:10.1002/anie.200390045

104.Ariga, K.; Lee, M. V.; Mori, T.; Yu, X.-Y.; Hill, J. P. Adv. Colloid Interface Sci. 2010, 154, 20-29. doi:10.1016/j.cis.2010.01.005

105. Ramanathan, M.; Hong, K.; Ji, Q.; Yonamine, Y.; Hill, J. P.; Ariga, K. J. Nanosci. Nanotechnol. 2014, 14, 390-401. doi:10.1166/jnn.2014.8766

106. Wakayama, Y. Jpn. J. Appl. Phys. 2016, 55, 1102AA. doi:10.7567/jjap.55.1102aa

107.Ariga, K.; Malgras, V.; Ji, Q.; Zakaria, M. B.; Yamauchi, Y. Coord. Chem. Rev. 2016, 320-321, 139-152. doi:10.1016/j.ccr.2016.01.015

108.Sangian, D.; Ide, Y.; Bando, Y.; Rowan, A. E.; Yamauchi, Y. Small 2018, 14, 1800551. doi:10.1002/smll.201800551

109. Ishihara, S.; Labuta, J.; Van Rossom, W.; Ishikawa, D.; Minami, K.; Hill, J. P.; Ariga, K. Phys. Chem. Chem. Phys. 2014, 16, 9713-9746. doi:10.1039/c3cp55431g

110.Ariga, K.; Yamauchi, Y.; Ji, Q.; Yonamine, Y.; Hill, J. P. APL Mater. 2014, 2, 030701. doi:10.1063/1.4868177

111. Ariga, K.; Minami, K.; Shrestha, L. K. Analyst 2016, 141, 2629-2638. doi:10.1039/c6an00057f

112.Jackman, J. A.; Cho, N.-J.; Nishikawa, M.; Yoshikawa, G.; Mori, T.; Shrestha, L. K.; Ariga, K. Chem. - Asian J. 2018, 13, 3366-3377. doi:10.1002/asia.201800935

113. Rajendran, R.; Shrestha, L. K.; Minami, K.; Subramanian, M.; Jayavel, R.; Ariga, K. J. Mater. Chem. A 2014, 2, 18480-18487. doi:10.1039/c4ta03996c

114. Rajendran, R.; Shrestha, L. K.; Kumar, R. M.; Jayavel, R.; Hill, J. P.; Ariga, K. J. Inorg. Organomet. Polym. Mater. 2015, 25, 267-274. doi:10.1007/s10904-014-0102-4

115.Chen, R.; Zhao, T.; Zhang, X.; Li, L.; Wu, F. Nanoscale Horiz. 2016, 1 , 423-444. doi:10.1039/c6nh00016a

116. Kim, J.; Kim, J. H.; Ariga, K. Joule 2017, 1, 739-768. doi:10.1016/j.joule.2017.08.018
117.Shrestha, L. K.; Shrestha, R. G.; Joshi, S.; Rajbhandari, R.; Shrestha, N.; Adhikari, M. P.; Pradhananga, R. R.; Ariga, K. J. Inorg. Organomet. Polym. Mater. 2017, 27 (Suppl. 1), 48-56. doi:10.1007/s10904-017-0548-2

118. Ariga, K.; Ishihara, S.; Abe, H.; Li, M.; Hill, J. P. J. Mater. Chem. 2012, 22, 2369-2377. doi:10.1039/c1jm14101e

119. Puscasu, C. M.; Carja, G.; Zaharia, C. Int. J. Mater. Prod. Technol. 2015, 51, 228-240. doi:10.1504/ijmpt.2015.072239

120. Ariga, K.; Ishihara, S.; Abe, H. CrystEngComm 2016, 18, 6770-6778. doi:10.1039/c6ce00986g

121.Wang, H.; Yin, S.; Eid, K.; Li, Y.; Xu, Y.; Li, X.; Xue, H.; Wang, L. ACS Sustainable Chem. Eng. 2018, 6, 11768-11774. doi:10.1021/acssuschemeng.8b02015

122. Ariga, K.; Ji, Q.; Mori, T.; Naito, M.; Yamauchi, Y.; Abe, H.; Hill, J. P. Chem. Soc. Rev. 2013, 42, 6322-6345. doi:10.1039/c2cs35475f

123. Nakanishi, W.; Minami, K.; Shrestha, L. K.; Ji, Q.; Hill, J. P.; Ariga, K. Nano Today 2014, 9, 378-394. doi:10.1016/j.nantod.2014.05.002

124. Ariga, K.; Kawakami, K.; Ebara, M.; Kotsuchibashi, Y.; Ji, Q.; Hill, J. P. New J. Chem. 2014, 38, 5149-5163. doi:10.1039/c4nj00864b

125.Pandey, A. P.; Girase, N. M.; Patil, M. D.; Patil, P. O.; Patil, D. A.; Deshmukh, P. K. J. Nanosci. Nanotechnol. 2014, 14, 828-840. doi:10.1166/jnn.2014.9014

126. Ariga, K.; Naito, M.; Ji, Q.; Payra, D. CrystEngComm 2016, 18 , 4890-4899. doi:10.1039/c6ce00432f

127.Nayak, A.; Unayama, S.; Tai, S.; Tsuruoka, T.; Waser, R.; Aono, M.; Valov, I.; Hasegawa, T. Adv. Mater. (Weinheim, Ger.) 2018, 30, 1703261. doi:10.1002/adma.201703261

128. Yan, Y.; Ye, J.; Wang, K.; Yao, J.; Zhao, Y. S. Small 2018, 14 , 1702698. doi:10.1002/smll.201702698

129.Stulz, E. Acc. Chem. Res. 2017, 50, 823-831. doi:10.1021/acs.accounts.6b00583

130. Pandeeswar, M.; Senanayak, S. P.; Govindaraju, T. ACS Appl. Mater. Interfaces 2016, 8, 30362-30371. doi:10.1021/acsami.6b10527

131.Zhang, L.; Wang, T.; Shen, Z.; Liu, M. Adv. Mater. (Weinheim, Ger.) 2016, 28, 1044-1059. doi:10.1002/adma.201502590

132.Zhao, L.; Zou, Q.; Yan, X. Bull. Chem. Soc. Jpn. 2019, 92, 70-79. doi:10.1246/bcsj.20180248

133. Abe, H.; Liu, J.; Ariga, K. Mater. Today 2016, 19, $12-18$. doi:10.1016/j.mattod.2015.08.021

134. Osada, M.; Sasaki, T. Dalton Trans. 2018, 47, 2841-2851. doi:10.1039/c7dt03719h

135.Xu, J.; Zhang, J.; Zhang, W.; Lee, C.-S. Adv. Energy Mater. 2017, 7, 1700571. doi:10.1002/aenm.201700571

136. Mathesh, M.; Liu, J.; Barrow, C. J.; Yang, W. Chem. - Eur. J. 2017, 23, 304-311. doi:10.1002/chem.201604348

137. Ariga, K.; Yamauchi, Y.; Mori, T.; Hill, J. P. Adv. Mater. (Weinheim, Ger.) 2013, 25, 6477-6512. doi:10.1002/adma.201302283

138. Ariga, K.; Mori, T.; Nakanishi, W. Chem. - Asian J. 2018, 13 , 1266-1278. doi:10.1002/asia.201800225

139. Ariga, K.; Ishihara, S.; Izawa, H.; Xia, H.; Hill, J. P. Phys. Chem. Chem. Phys. 2011, 13, 4802-4811. doi:10.1039/c0cp02040k

140. Ariga, K.; Hill, J. P. Chem. Rec. 2011, 11, 199-211. doi:10.1002/tcr.201100004

141. Ariga, K.; Mori, T.; Hill, J. P. Soft Matter 2012, 8, 15-20. doi:10.1039/c1sm06832f

142. Ariga, K.; Kunitake, T. Acc. Chem. Res. 1998, 31, 371-378. doi:10.1021/ar970014i 
143.Ariga, K.; Ito, H.; Hill, J. P.; Tsukube, H. Chem. Soc. Rev. 2012, 41 , 5800-5835. doi:10.1039/c2cs35162e

144. Ariga, K.; Mori, T.; Li, J. Langmuir 2019, 35, 3585-3599. doi:10.1021/acs.langmuir.8b01434

145. Kurihara, K.; Ohto, K.; Tanaka, Y.; Aoyama, Y.; Kunitake, T. Thin Solid Films 1989, 179, 21-26. doi:10.1016/0040-6090(89)90160-0

146. Kurihara, K.; Ohto, K.; Tanaka, Y.; Aoyama, Y.; Kunitake, T. J. Am. Chem. Soc. 1991, 113, 444-450. doi:10.1021/ja00002a010

147. Cha, X.; Ariga, K.; Onda, M.; Kunitake, T. J. Am. Chem. Soc. 1995, 117, 11833-11838. doi:10.1021/ja00153a003

148. Cha, X.; Ariga, K.; Kunitake, T. J. Am. Chem. Soc. 1996, 118, 9545-9551. doi:10.1021/ja961526f

149.Ariga, K.; Kamino, A.; Cha, X.; Kunitake, T. Langmuir 1999, 15, 3875-3885. doi:10.1021/la981047p

150. Ikeura, Y.; Kurihara, K.; Kunitake, T. J. Am. Chem. Soc. 1991, 113, 7342-7350. doi:10.1021/ja00019a035

151. Kurihara, K.; Ohto, K.; Honda, Y.; Kunitake, T. J. Am. Chem. Soc. 1991, 113, 5077-5079. doi:10.1021/ja00013a063

152. Kawahara, T.; Kurihara, K.; Kunitake, T. Chem. Lett. 1992, 21 , 1839-1842. doi:10.1246/cl.1992.1839

153. Taguchi, K.; Ariga, K.; Kunitake, T. Chem. Lett. 1995, 24, 701-702. doi:10.1246/cl.1995.701

154.Ariga, K.; Kamino, A.; Koyano, H.; Kunitake, T. J. Mater. Chem. 1997, 7, 1155-1161. doi:10.1039/a700081b

155. Onda, M.; Yoshihara, K.; Koyano, H.; Ariga, K.; Kunitake, T. J. Am. Chem. Soc. 1996, 118, 8524-8530. doi:10.1021/ja960991+

156.Springs, B.; Haake, P. Bioorg. Chem. 1977, 6, 181-190. doi:10.1016/0045-2068(77)90019-0

157.Sasaki, D. Y.; Kurihara, K.; Kunitake, T. J. Am. Chem. Soc. 1991, 113, 9685-9686. doi:10.1021/ja00025a051

158.Sasaki, D. Y.; Kurihara, K.; Kunitake, T. J. Am. Chem. Soc. 1992, 114, 10994-10995. doi:10.1021/ja00053a065

159.Sakurai, M.; Tamagawa, H.; Furuki, T.; Inoue, Y.; Ariga, K.; Kunitake, T. Chem. Lett. 1995, 24, 1001-1002. doi:10.1246/cl.1995.1001

160.Sakurai, M.; Tamagawa, H.; Inoue, Y.; Ariga, K.; Kunitake, T. J. Phys. Chem. B 1997, 101, 4810-4816. doi:10.1021/jp9700591

161. Tamagawa, H.; Sakurai, M.; Inoue, Y.; Ariga, K.; Kunitake, T. J. Phys. Chem. B 1997, 101, 4817-4825. doi:10.1021/jp9700600

162. Ariga, K. ChemNanoMat 2016, 2, 333-343. doi:10.1002/cnma.201600053

163. Ariga, K.; Mori, T.; Hill, J. P. Adv. Mater. (Weinheim, Ger.) 2012, 24 , 158-176. doi:10.1002/adma.201102617

164.Ariga, K.; Mori, T.; Hill, J. P. Langmuir 2013, 29, 8459-8471. doi:10.1021/la4006423

165. Ariga, K.; Mori, T.; Ishihara, S.; Kawakami, K.; Hill, J. P. Chem. Mater. 2014, 26, 519-532. doi:10.1021/cm401999f

166. Ariga, K. Anal. Sci. 2016, 32, 1141-1149. doi:10.2116/analsci.32.1141

167.Ariga, K.; Terasaka, Y.; Sakai, D.; Tsuji, H.; Kikuchi, J.-i. J. Am. Chem. Soc. 2000, 122, 7835-7836. doi:10.1021/ja000924m

168. Ariga, K.; Nakanishi, T.; Terasaka, Y.; Tsuji, H.; Sakai, D.; Kikuchi, J.-i. Langmuir 2005, 21, 976-981. doi:10.1021/la0477845

169. Mori, T.; Komatsu, H.; Sakamoto, N.; Suzuki, K.; Hill, J. P.; Matsumoto, M.; Sakai, H.; Ariga, K.; Nakanishi, W. Phys. Chem. Chem. Phys. 2018, 20, 3073-3078. doi:10.1039/c7cp04256f

170.Mori, T.; Chin, H.; Kawashima, K.; Ngo, H.; Cho, N.-J.; Nakanishi, W.; Hill, J. P.; Ariga, K. ACS Nano 2019, 13, 2410-2419. doi:10.1021/acsnano.8b09320
171.Ishikawa, D.; Mori, T.; Yonamine, Y.; Nakanishi, W.; Cheung, D. L.; Hill, J. P.; Ariga, K. Angew. Chem., Int. Ed. 2015, 54, 8988-8991. doi:10.1002/anie.201503363

172. Mori, T.; Ishikawa, D.; Yonamine, Y.; Fujii, Y.; Hill, J. P.; Ichinose, I.; Ariga, K.; Nakanishi, W. ChemPhysChem 2017, 18, 1470-1474. doi:10.1002/cphc.201601144

173.Sakakibara, K.; Joyce, L. A.; Mori, T.; Fujisawa, T.; Shabbir, S. H.; Hill, J. P.; Anslyn, E. V.; Ariga, K. Angew. Chem., Int. Ed. 2012, 51, 9643-9646. doi:10.1002/anie.201203402

174. Michinobu, T.; Shinoda, S.; Nakanishi, T.; Hill, J. P.; Fujii, K.; Player, T. N.; Tsukube, H.; Ariga, K. J. Am. Chem. Soc. 2006, 128, 14478-14479. doi:10.1021/ja066429t

175. Michinobu, T.; Shinoda, S.; Nakanishi, T.; Hill, J. P.; Fujii, K.; Player, T. N.; Tsukube, H.; Ariga, K. Phys. Chem. Chem. Phys. 2011, 13, 4895-4900. doi:10.1039/c0cp01990a

176.Mori, T.; Okamoto, K.; Endo, H.; Hill, J. P.; Shinoda, S.; Matsukura, M.; Tsukube, H.; Suzuki, Y.; Kanekiyo, Y.; Ariga, K. J. Am. Chem. Soc. 2010, 132, 12868-12870. doi:10.1021/ja106653a

177.Mori, T.; Okamoto, K.; Endo, H.; Sakakibara, K.; Hill, J. P.; Shinoda, S.; Matsukura, M.; Tsukube, H.; Suzuki, Y.; Kanekiyo, Y.; Ariga, K. Nanoscale Res. Lett. 2011, 6, 304. doi:10.1186/1556-276x-6-304

178. Ariga, K.; Minami, K.; Ebara, M.; Nakanishi, J. Polym. J. 2016, 48, 371-389. doi:10.1038/pj.2016.8

179. Ariga, K.; Mori, T.; Nakanishi, W.; Hill, J. P. Phys. Chem. Chem. Phys. 2017, 19, 23658-23676. doi:10.1039/c7cp02280h

180. Shrestha, L. K.; Mori, T.; Ariga, K. Curr. Opin. Colloid Interface Sci. 2018, 35, 68-80. doi:10.1016/j.cocis.2018.01.007

181.Lehn, J.-M. Angew. Chem., Int. Ed. Engl. 1988, 27, 89-112. doi:10.1002/anie.198800891

182. Cram, D. J. Angew. Chem., Int. Ed. Engl. 1988, 27, 1009-1020. doi:10.1002/anie. 198810093

183.Pedersen, C. J. Angew. Chem., Int. Ed. Engl. 1988, 27, 1021-1027. doi:10.1002/anie.198810211

184. Shinkai, S.; Ogawa, T.; Nakaji, T.; Kusano, Y.; Nanabe, O. Tetrahedron Lett. 1979, 20, 4569-4572. doi:10.1016/s0040-4039(01)86651-x

185. Ueda, A. Bull. Chem. Soc. Jpn. 2017, 90, 1181-1188. doi:10.1246/bcsj.20170239

186. Gropp, C.; Quigley, B. L.; Diederich, F. J. Am. Chem. Soc. 2018, 140, 2705-2717. doi:10.1021/jacs.7b12894

187.Irie, M.; Morimoto, M. Bull. Chem. Soc. Jpn. 2018, 91, 237-250. doi:10.1246/bcsj.20170365

188. Park, J. S.; Sessler, J. L. Acc. Chem. Res. 2018, 51, 2400-2410. doi:10.1021/acs.accounts.8b00308

189.Stoddart, J. F. Angew. Chem., Int. Ed. 2017, 56, 11094-11125. doi:10.1002/anie.201703216

190. Feringa, B. L. Angew. Chem., Int. Ed. 2017, 56, 11060-11078. doi:10.1002/anie.201702979

191.Sauvage, J.-P. Angew. Chem., Int. Ed. 2017, 56, 11080-11093. doi:10.1002/anie.201702992

192. Ariga, K. J. Nanosci. Nanotechnol. 2004, 4, 23-34. doi:10.1166/jnn.2004.048

193. Ariga, K. J. Photopolym. Sci. Technol. 2008, 21, 553-558. doi:10.2494/photopolymer.21.553

194.Oishi, Y.; Torii, Y.; Kuramori, M.; Suehiro, K.; Ariga, K.; Taguchi, K.; Kamino, A.; Kunitake, T. Chem. Lett. 1996, 25, 411-412. doi:10.1246/cl.1996.411 
195. Oishi, Y.; Torii, Y.; Kato, T.; Kuramori, M.; Suehiro, K.; Ariga, K.; Taguchi, K.; Kamino, A.; Koyano, H.; Kunitake, T. Langmuir 1997, 13 , 519-524. doi:10.1021/la960112x

196. Oishi, Y.; Kato, T.; Kuramori, M.; Suehiro, K.; Ariga, K.; Kamino, A.; Koyano, H.; Kunitake, T. Chem. Commun. 1997, 1357-1358. doi:10.1039/a702880f

197.Koyano, H.; Yoshihara, K.; Ariga, K.; Kunitake, T.; Oishi, Y.; Kawano, O.; Kuramori, M.; Suehiro, K. Chem. Commun. 1996, 1769-1770. doi:10.1039/cc9960001769

198. Oishi, Y.; Kato, T.; Narita, T.; Ariga, K.; Kunitake, T. Langmuir 2008, 24, 1682-1685. doi:10.1021/la7036372

199.Liu, X.; Riess, J. G.; Krafft, M. P. Bull. Chem. Soc. Jpn. 2018, 91 , 846-857. doi:10.1246/bcsj.20170431

200.Richard-Lacroix, M.; Borozenko, K.; Pellerin, C.; Bazuin, C. G. Macromolecules 2016, 49, 9089-9099. doi:10.1021/acs.macromol.6b01980

201.Wu, T.; Wen, G.; Huang, C. J. Polym. Sci., Part B: Polym. Phys. 2016, 54, 825-830. doi:10.1002/polb.23979

202.Mori, T.; Sakakibara, K.; Endo, H.; Akada, M.; Okamoto, K.; Shundo, A.; Lee, M. V.; Ji, Q.; Fujisawa, T.; Oka, K.; Matsumoto, M.; Sakai, H.; Abe, M.; Hill, J. P.; Ariga, K. Langmuir 2013, 29 , 7239-7248. doi:10.1021/la304293z

203.Das, T.; Häring, M.; Haldar, D.; Díaz Díaz, D. Biomater. Sci. 2018, 6 , 38-59. doi:10.1039/c7bm00882a

204. Hanabusa, K.; Nakashima, M.; Funatsu, E.; Kishi, S.; Suzuki, M. Bull. Chem. Soc. Jpn. 2018, 91, 1176-1185. doi:10.1246/bcsj.20180072

205. Ganta, S.; Chand, D. K. Chem. - Asian J. 2018, 13, 3777-3789. doi:10.1002/asia.201801161

206.Sasaki, J.; Suzuki, M.; Hanabusa, K. Bull. Chem. Soc. Jpn. 2018, 91 , 538-547. doi:10.1246/bcsj.20170409

207.Cherumukkil, S.; Vedhanarayanan, B.; Das, G.; Praveen, V. K.; Ajayaghosh, A. Bull. Chem. Soc. Jpn. 2018, 91, 100-120. doi:10.1246/bcsj.20170334

208.Sakakibara, K.; Chithra, P.; Das, B.; Mori, T.; Akada, M.; Labuta, J.; Tsuruoka, T.; Maji, S.; Furumi, S.; Shrestha, L. K.; Hill, J. P.; Acharya, S.; Ariga, K.; Ajayaghosh, A. J. Am. Chem. Soc. 2014, 136, 8548-8551. doi:10.1021/ja504014k

209. Vinu, A.; Srinivasu, P.; Sawant, D. P.; Mori, T.; Ariga, K.; Chang, J.-S.; Jhung, S.-H.; Balasubramanian, V. V.; Hwang, Y. K. Chem. Mater. 2007, 19, 4367-4372. doi:10.1021/cm070657k

210.Ariga, K.; Ji, Q.; McShane, M. J.; Lvov, Y. M.; Vinu, A.; Hill, J. P. Chem. Mater. 2012, 24, 728-737. doi:10.1021/cm202281m

211. Chaikittisilp, W.; Ariga, K.; Yamauchi, Y. J. Mater. Chem. A 2013, 1 , 14-19. doi:10.1039/c2ta00278g

212.Zhang, J.; Yang, X.; Deng, H.; Qiao, K.; Farooq, U.; Ishaq, M.; Yi, F.; Liu, H.; Tang, J.; Song, H. Nano-Micro Lett. 2017, 9, 36. doi:10.1007/s40820-017-0137-5

213.Jeevanandam, J.; Barhoum, A.; Chan, Y. S.; Dufresne, A.; Danquah, M. K. Beilstein J. Nanotechnol. 2018, 9, 1050-1074. doi:10.3762/bjnano.9.98

214.Smith, M. D.; Karunadasa, H. I. Acc. Chem. Res. 2018, 51, 619-627. doi:10.1021/acs.accounts.7b00433

215. Ogawa, S.; Wakayama, T.; Watanabe, H.; Hayashi, K.; Ogata, S.; Oaki, Y.; Hasegawa, M.; Imai, H. Bull. Chem. Soc. Jpn. 2018, 91, 87-91. doi:10.1246/bcsj.20170291

216.Cheng, W.; Ju, Y.; Payamyar, P.; Primc, D.; Rao, J.; Willa, C.; Koziej, D.; Niederberger, M. Angew. Chem., Int. Ed. 2015, 54, 340-344. doi:10.1002/anie.201408617
217. Tiu, B. D. B.; Pernites, R. B.; Foster, E. L.; Advincula, R. C. J. Colloid Interface Sci. 2015, 459, 86-96. doi:10.1016/j.jcis.2015.08.004

218. Nie, H.-L.; Dou, X.; Tang, Z.; Jang, H. D.; Huang, J. J. Am. Chem. Soc. 2015, 137, 10683-10688. doi:10.1021/jacs.5b06052

219. Yonamine, Y.; Cervantes-Salguero, K.; Minami, K.; Kawamata, I.; Nakanishi, W.; Hill, J. P.; Murata, S.; Ariga, K. Phys. Chem. Chem. Phys. 2016, 18, 12576-12581. doi:10.1039/c6cp01586g

220.Wang, L.; Sahabudeen, H.; Zhang, T.; Dong, R. npj 2D Mater. Appl. 2018, 2, 26. doi:10.1038/s41699-018-0071-5

221.Culp, J. T.; Park, J.-H.; Stratakis, D.; Meisel, M. W.; Talham, D. R. J. Am. Chem. Soc. 2002, 124, 10083-10090. doi:10.1021/ja026312e

222. Makiura, R.; Motoyama, S.; Umemura, Y.; Yamanaka, H.; Sakata, O.; Kitagawa, H. Nat. Mater. 2010, 9, 565-571. doi:10.1038/nmat2769

223.Wu, G.; Huang, J.; Zang, Y.; He, J.; Xu, G. J. Am. Chem. Soc. 2017, 139, 1360-1363. doi:10.1021/jacs.6b08511

224. Feldblyum, J. I.; McCreery, C. H.; Andrews, S. C.; Kurosawa, T.; Santos, E. J. G.; Duong, V.; Fang, L.; Ayzner, A. L.; Bao, Z. Chem. Commun. 2015, 51, 13894-13897. doi:10.1039/c5cc04679c

225.Dai, W.; Shao, F.; Szczerbiński, J.; McCaffrey, R.; Zenobi, R.; Jin, Y.; Schlüter, A. D.; Zhang, W. Angew. Chem., Int. Ed. 2016, 55, 213-217. doi:10.1002/anie.201508473

226. Kambe, T.; Sakamoto, R.; Hoshiko, K.; Takada, K.; Miyachi, M.; Ryu, J.-H.; Sasaki, S.; Kim, J.; Nakazato, K.; Takata, M.; Nishihara, H. J. Am. Chem. Soc. 2013, 135, 2462-2465. doi:10.1021/ja312380b

227.Takada, K.; Sakamoto, R.; Yi, S.-T.; Katagiri, S.; Kambe, T.; Nishihara, H. J. Am. Chem. Soc. 2015, 137, 4681-4689. doi:10.1021/ja510788b

228. Sahabudeen, H.; Qi, H.; Glatz, B. A.; Tranca, D.; Dong, R.; Hou, Y.; Zhang, T.; Kuttner, C.; Lehnert, T.; Seifert, G.; Kaiser, U.; Fery, A.; Zheng, Z.; Feng, X. Nat. Commun. 2016, 7, 13461. doi:10.1038/ncomms13461

229.Dey, K.; Pal, M.; Rout, K. C.; Kunjattu H, S.; Das, A.; Mukherjee, R.; Kharul, U. K.; Banerjee, R. J. Am. Chem. Soc. 2017, 139, 13083-13091. doi:10.1021/jacs.7b06640

230. Matsumoto, M.; Valentino, L.; Stiehl, G. M.; Balch, H. B.; Corcos, A. R.; Wang, F.; Ralph, D. C.; Mariñas, B. J.; Dichtel, W. R. Chem 2018, 4, 308-317. doi:10.1016/j.chempr.2017.12.011

231. Matsumoto, M.; Dasari, R. R.; Ji, W.; Feriante, C. H.; Parker, T. C.; Marder, S. R.; Dichtel, W. R. J. Am. Chem. Soc. 2017, 139, 4999-5002. doi:10.1021/jacs.7b01240

232. Valentino, L.; Matsumoto, M.; Dichtel, W. R.; Mariñas, B. J. Environ. Sci. Technol. 2017, 51, 14352-14359. doi:10.1021/acs.est.7b04056

233.Sarikhani, Z.; Manoochehri, M. Bull. Chem. Soc. Jpn. 2017, 90, 746-753. doi:10.1246/bcsj.20160407

234. Mori, T.; Tanaka, H.; Dalui, A.; Mitoma, N.; Suzuki, K.; Matsumoto, M.; Aggarwal, N.; Patnaik, A.; Acharya, S.; Shrestha, L. K.; Sakamoto, H.; Itami, K.; Ariga, K. Angew. Chem., Int. Ed. 2018, 57, 9679-9683. doi:10.1002/anie.201803859

235. Nakanishi, T.; Michinobu, T.; Yoshida, K.; Shirahata, N.; Ariga, K.; Möhwald, H.; Kurth, D. G. Adv. Mater. (Weinheim, Ger.) 2008, 20, 443-446. doi:10.1002/adma.200701537

236. Shrestha, L. K.; Shrestha, R. G.; Hill, J. P.; Ariga, K. J. Oleo Sci. 2013, 62, 541-553. doi:10.5650/jos.62.541

237. Miyazawa, K.; Kuwasaki, Y.; Hamamoto, K.; Nagata, S.; Obayashi, A.; Kuwabara, M. Surf. Interface Anal. 2003, 35, 117-120. doi:10.1002/sia.1506 
238.Shrestha, L. K.; Ji, Q.; Mori, T.; Miyazawa, K.; Yamauchi, Y.; Hill, J. P.; Ariga, K. Chem. - Asian J. 2013, 8, 1662-1679. doi:10.1002/asia.201300247

239. Miyazawa, K. Sci. Technol. Adv. Mater. 2015, 16, 013502. doi:10.1088/1468-6996/16/1/013502

240.Shrestha, L. K.; Hill, J. P.; Miyazawa, K.; Ariga, K. J. Nanosci. Nanotechnol. 2012, 12, 6380-6384. doi:10.1166/jnn.2012.6220

241.Shrestha, L. K.; Hill, J. P.; Tsuruoka, T.; Miyazawa, K.; Ariga, K. Langmuir 2013, 29, 7195-7202. doi:10.1021/la304549v

242.Shrestha, L. K.; Shrestha, R. G.; Yamauchi, Y.; Hill, J. P.; Nishimura, T.; Miyazawa, K.; Kawai, T.; Okada, S.; Wakabayashi, K.; Ariga, K. Angew. Chem., Int. Ed. 2015, 54, 951-955. doi:10.1002/anie.201408856

243.Bairi, P.; Shrestha, R. G.; Hill, J. P.; Nishimura, T.; Ariga, K.; Shrestha, L. K. J. Mater. Chem. A 2016, 4, 13899-13906. doi:10.1039/c6ta04970b

244.Shrestha, R. G.; Shrestha, L. K.; Khan, A. H.; Kumar, G. S.; Acharya, S.; Ariga, K. ACS Appl. Mater. Interfaces 2014, 6, 15597-15603. doi:10.1021/am5046235

245.Tang, Q.; Zhang, S.; Liu, X.; Sumita, M.; Ishihara, S.; Fuchs, H.; Ji, Q.; Shrestha, L. K.; Ariga, K. Phys. Chem. Chem. Phys. 2017, 19, 29099-29105. doi:10.1039/c7cp04553k

246.Kumar, G. S.; Shrestha, R. G.; Ji, Q.; Hill, J. P.; Ariga, K.; Acharya, S.; Shrestha, L. K. Phys. Chem. Chem. Phys. 2018, 20, 18873-18878. doi:10.1039/c8cp02779j

247.Furuuchi, N.; Shrestha, R.; Yamashita, Y.; Hirao, T.; Ariga, K.; Shrestha, L. Sensors 2019, 19, 267. doi:10.3390/s19020267

248.Saran, R.; Curry, R. J. Small 2018, 14, 1703624. doi:10.1002/smll.201703624

249.Shen, W.; Zhang, L.; Zheng, S.; Xie, Y.; Lu, X. ACS Appl. Mater. Interfaces 2017, 9, 28838-28843. doi:10.1021/acsami.7b05180

250.Shrestha, L. K.; Yamauchi, Y.; Hill, J. P.; Miyazawa, K.; Ariga, K. J. Am. Chem. Soc. 2013, 135, 586-589. doi:10.1021/ja3108752

251.Tang, Q.; Bairi, P.; Shrestha, R. G.; Hill, J. P.; Ariga, K.; Zeng, H.; Ji, Q.; Shrestha, L. K. ACS Appl. Mater. Interfaces 2017, 9, 44458-44465. doi:10.1021/acsami.7b13277

252.Shrestha, L. K.; Sathish, M.; Hill, J. P.; Miyazawa, K.; Tsuruoka, T.; Sanchez-Ballester, N. M.; Honma, I.; Ji, Q.; Ariga, K. J. Mater. Chem. C 2013, 1, 1174-1181. doi:10.1039/c2tc00449f

253.Bairi, P.; Minami, K.; Nakanishi, W.; Hill, J. P.; Ariga, K.; Shrestha, L. K. ACS Nano 2016, 10, 6631-6637. doi:10.1021/acsnano.6b01544

254.Bairi, P.; Minami, K.; Hill, J. P.; Ariga, K.; Shrestha, L. K. ACS Nano 2017, 11, 7790-7796. doi:10.1021/acsnano.7b01569

255.Bairi, P.; Tsuruoka, T.; Acharya, S.; Ji, Q.; Hill, J. P.; Ariga, K.; Yamauchi, Y.; Shrestha, L. K. Mater. Horiz. 2018, 5, 285-290. doi:10.1039/c7mh00954b

256. Shrestha, L. K.; Shrestha, R. G.; Hill, J. P.; Tsuruoka, T.; Ji, Q.; Nishimura, T.; Ariga, K. Langmuir 2016, 32, 12511-12519. doi:10.1021/acs.langmuir.6b01378

257.Wang, B.; Zheng, S.; Saha, A.; Bao, L.; Lu, X.; Guldi, D. M. J. Am. Chem. Soc. 2017, 139, 10578-10584. doi:10.1021/jacs.7b06162

258.Zhou, S.; Wang, L.; Chen, M.; Liu, B.; Sun, X.; Cai, M.; Li, H. Nanoscale 2017, 9, 16375-16385. doi:10.1039/c7nr06112a

259. Bairi, P.; Minami, K.; Hill, J. P.; Nakanishi, W.; Shrestha, L. K.; Liu, C.; Harano, K.; Nakamura, E.; Ariga, K. ACS Nano 2016, 10, 8796-8802. doi:10.1021/acsnano.6b04535
260. Komiyama, M.; Yoshimoto, K.; Sisido, M.; Ariga, K. Bull. Chem. Soc. Jpn. 2017, 90, 967-1004. doi:10.1246/bcsj.20170156

261. Ariga, K.; Leong, D. T.; Mori, T. Adv. Funct. Mater. 2018, 28 , 1702905. doi:10.1002/adfm.201702905

262. Ariga, K.; Jackman, J. A.; Cho, N.-J.; Hsu, S.-h.; Shrestha, L. K.; Mori, T.; Takeya, J. Chem. Rec., in press. doi:10.1002/tcr.201800103

263. Matsuura, K. Bull. Chem. Soc. Jpn. 2017, 90, 873-884. doi:10.1246/bcsj.20170133

264.Sawada, T.; Serizawa, T. Bull. Chem. Soc. Jpn. 2018, 91, 455-466. doi:10.1246/bcsj.20170428

265. He, H.; Xu, B. Bull. Chem. Soc. Jpn. 2018, 91, 900-906. doi:10.1246/bcsj.20180038

266. Fromherz, P. Biochim. Biophys. Acta, Biomembr. 1971, 225, 382-387. doi:10.1016/0005-2736(71)90235-5

267. Fromherz, P. Rev. Sci. Instrum. 1975, 46, 1380-1385. doi:10.1063/1.1134025

268. Okahata, Y.; Tsuruta, T.; ljiro, K.; Ariga, K. Langmuir 1988, 4, 1373-1375. doi:10.1021/la00084a030

269. Okahata, Y.; Tsuruta, T.; Ijiro, K.; Ariga, K. Thin Solid Films 1989, 180 65-72. doi:10.1016/0040-6090(89)90055-2

270. Ariga, K.; Hill, J. P.; Ji, Q. Phys. Chem. Chem. Phys. 2007, 9 , 2319-2340. doi:10.1039/b700410a

271.Ariga, K.; Lvov, Y. M.; Kawakami, K.; Ji, Q.; Hill, J. P. Adv. Drug Delivery Rev. 2011, 63, 762-771. doi:10.1016/j.addr.2011.03.016

272.Ariga, K.; Yamauchi, Y.; Rydzek, G.; Ji, Q.; Yonamine, Y.; Wu, K. C.-W.; Hill, J. P. Chem. Lett. 2014, 43, 36-68. doi:10.1246/cl.130987

273.Rydzek, G.; Ji, Q.; Li, M.; Schaaf, P.; Hill, J. P.; Boulmedais, F.; Ariga, K. Nano Today 2015, 10, 138-167. doi:10.1016/j.nantod.2015.02.008

274. Onda, M.; Lvov, Y.; Ariga, K.; Kunitake, T. J. Ferment. Bioeng. 1996, 82, 502-506. doi:10.1016/s0922-338x(97)86992-9

275. Onda, M.; Lvov, Y.; Ariga, K.; Kunitake, T. Biotechnol. Bioeng. 1996, $51,163-167$. doi:10.1002/(sici)1097-0290(19960720)51:2<163::aid-bit5>3.0.co;2-h

276. Onda, M.; Ariga, K.; Kunitake, T. J. Biosci. Bioeng. 1999, 87, 69-75. doi:10.1016/s1389-1723(99)80010-3

277.Minami, K.; Mori, T.; Nakanishi, W.; Shigi, N.; Nakanishi, J.; Hill, J. P.; Komiyama, M.; Ariga, K. ACS Appl. Mater. Interfaces 2017, 9 , 30553-30560. doi:10.1021/acsami.7b11445

278. Giaever, I.; Keese, C. R. Proc. Natl. Acad. Sci. U. S. A. 1983, 80, 219-222. doi:10.1073/pnas.80.1.219

279. Keese, C. R.; Giaever, I. Proc. Natl. Acad. Sci. U. S. A. 1983, 80 , 5622-5626. doi:10.1073/pnas.80.18.5622

280. Keese, C. R.; Giaever, I. Exp. Cell Res. 1991, 195, 528-532. doi:10.1016/0014-4827(91)90406-k

281. Shiba, Y.; Ohshima, T.; Sato, M. Kagaku Kogaku Ronbunshu 1998, 24, 343-345. doi:10.1252/kakoronbunshu.24.343

282.Shiba, Y.; Ohshima, T.; Sato, M. Biotechnol. Bioeng. 1998, 57, 583-589. doi:10.1002/(sici)1097-0290(19980305)57:5<583::aid-bit10>3.0.co;2-d

283. Sato, M.; Shinozawa, T.; Ueno, H.; Sadakata, M. Kagaku Kogaku Ronbunshu 1991, 17, 671-673. doi:10.1252/kakoronbunshu.17.671

284.Ando, J.; Albelda, S. M.; Levine, E. M. In Vitro Cell. Dev. Biol.: Anim. 1991, 27, 525-532. doi:10.1007/bf02631282 
285. Pilarek, M.; Grabowska, I.; Ciemerych, M. A.; Dąbkowska, K.; Szewczyk, K. W. Biotechnol. Lett. 2013, 35, 1387-1394.

doi:10.1007/s10529-013-1218-2

286.Kong, D.; Megone, W.; Nguyen, K. D. Q.; Di Cio, S.; Ramstedt, M.; Gautrot, J. E. Nano Lett. 2018, 18, 1946-1951.

doi:10.1021/acs.nanolett.7b05339

287.Kong, D.; Peng, L.; Di Cio, S.; Novak, P.; Gautrot, J. E. ACS Nano 2018, 12, 9206-9213. doi:10.1021/acsnano.8b03865

288.Jia, X.; Minami, K.; Uto, K.; Chang, A. C.; Hill, J. P.; Ueki, T.; Nakanishi, J.; Ariga, K. Small 2019, 15, 1804640. doi:10.1002/smll.201804640

289. Yang, F.; Tao, F.; Li, C.; Gao, L.; Yang, P. Nat. Commun. 2018, 9, 5443. doi:10.1038/s41467-018-07888-2

290. Krishnan, V.; Kasuya, Y.; Ji, Q.; Sathish, M.; Shrestha, L. K.; Ishihara, S.; Minami, K.; Morita, H.; Yamazaki, T.; Hanagata, N.; Miyazawa, K.; Acharya, S.; Nakanishi, W.; Hill, J. P.; Ariga, K. ACS Appl. Mater. Interfaces 2015, 7, 15667-15673. doi:10.1021/acsami.5b04811

291.Minami, K.; Kasuya, Y.; Yamazaki, T.; Ji, Q.; Nakanishi, W.; Hill, J. P.; Sakai, H.; Ariga, K. Adv. Mater. (Weinheim, Ger.) 2015, 27, 4020-4026. doi:10.1002/adma.201501690

292.Hsieh, F.-Y.; Shrestha, L. K.; Ariga, K.; Hsu, S.-h. Chem. Commun. 2017, 53, 11024-11027. doi:10.1039/c7cc06395d

293. Deisseroth, K. Nat. Methods 2011, 8, 26-29. doi:10.1038/nmeth.f.324

294.Luo, P.-W.; Han, H.-W.; Yang, C.-S.; Shrestha, L. K.; Ariga, K.; Hsu, S.-h. Adv. Biosyst. 2019, 3, 1800254. doi:10.1002/adbi.201800254

\section{License and Terms}

This is an Open Access article under the terms of the Creative Commons Attribution License (http://creativecommons.org/licenses/by/4.0). Please note that the reuse, redistribution and reproduction in particular requires that the authors and source are credited.

The license is subject to the Beilstein Journal of Nanotechnology terms and conditions:

(https://www.beilstein-journals.org/bjnano)

The definitive version of this article is the electronic one which can be found at: $\underline{\text { doi:10.3762/bjnano. } 10.153}$ 